Res Dev Disabil Vol. 27(3):254-289 (2006)

ISSN: (print 0891-4222)(online 1873-3379)

doi: $10.1016 /$ j.ridd.2005.03.003

This is a peer reviewed pre-print version of the following article: Neurochemical correlates of autistic disorder: A review of the literature, which has been published in final form at:

http://www.elsevier.com

http://www.elsevier.com/wps/find/journaldescription.cws_home/826/description\#description

http://www.sciencedirect.com/science/article/pii/S0891422205000557

(C) 2005 Elsevier Ltd.

\title{
Neurochemical correlates of autistic disorder: A review of the literature
}

\author{
Kristen S.L. Lam, Neurodevelopmental Disorders Research Center, University of \\ North Carolina at Chapel Hill, NC, USA, Michael G. Aman, The Nisonger Center, \\ The Ohio State University, 1581 Dodd Drive, Columbus, OH 43210, USA , L. Eugene \\ Arnold, The Nisonger Center, The Ohio State University, 1581 Dodd Drive, \\ Columbus, OH 43210, USA
}

\begin{abstract}
Review of neurochemical investigations in autistic disorder revealed that a wide array of transmitter systems have been studied, including serotonin, dopamine, norepinephrine, acetylcholine, oxytocin, endogenous opioids, cortisol, glutamate, and gamma-aminobutyric acid (GABA). These studies have been complicated by the fact that autism is a very heterogeneous disorder which often presents with comorbid behavioral problems. In addition, many of these studies employed very small samples and inappropriate control groups, making it difficult to draw conclusions with confidence. Overall, serotonin appears to have the most empirical evidence for a role in autism, but this requires further investigation and replication. There is little support for the notion that a dysfunction of norepinephrine or the endogenous opioids are related to autism. The role of dopaminergic functioning has not been compelling thus far, though conflicting findings on central dopamine turnover require further study. Promising new areas of study may include possible dysfunction of the cholinergic system, oxytocin, and amino acid neurotransmitters. Implications for pharmacotherapy are briefly discussed for each neurotransmitter system with brief research examples. Review of this work emphasizes the need for future studies to control for subject variables, such as race, sex, pubertal status, and distress associated with blood draws, which can affect measures of neurochemical function. In addition, research in neurochemistry must continue to work in concert with other subspecialties to form a more comprehensive and theory-based approach to the neurobiological correlates of autistic disorder.
\end{abstract}

\section{Neurochemical correlates of autistic disorder}

Autism is a pervasive developmental disorder characterized by impaired social interaction, deficits in verbal and nonverbal communication, and stereotyped interests and behaviors. Although the estimated prevalence in the general population ranges from 0.04 to $0.2 \%$ (Sponheim \& Skjeldal, 1998; Chakrabarti \& Fombonne, 2001), its emergence early in life, its profound impact on families, and its chronic course have resulted in enormous emotional and financial costs (Bristol et al., 1996). It is now widely accepted that autism is a neurobiological disorder, though specific biological markers have yet to be found. However, there are aspects of the disorder which may guide future investigations into its pathophysiology. First, this is a developmental syndrome that is always observed before 3 years of age. Some families have even reported abnormalities in social interests within the first few months of life (Lord, 1995). Therefore, relevant neurochemical or neuroanatomical events may occur relatively early in the development of the central nervous system (CNS). Affected individuals also exhibit a range of cognitive deficits, with approximately $75 \%$ functioning within the range of mental retardation (Gillberg \& Coleman, 1992). In addition, a substantial proportion (up to 50\%) of patients with autism have abnormal EEGs (Trottier, Srivastava, \& Walker, 1999), further suggesting underlying brain dysfunction. As is the case with 
many neurodevelopmental syndromes, boys are affected about four times more often than girls (Gillberg \& Coleman, 1992). There is now strong evidence that autism has a genetic component. Siblings of individuals with autism have a prevalence of 2.9 to $3.7 \%$, which represents a nearly 100-fold increased risk relative to the general population (Bolton et al., 1994; Jorde et al., 1990; Szatmari \& Jones, 1991). Twin studies have found concordance among monozygotic twins to range between 36 and 91\%, whereas concordance in dizygotic twins was 1\% (Bailey et al., 1995; Steffenberg et al., 1989). It is not clear why Bailey et al. and Steffenberg et al. found rates less than $1 \%$ for dizygotic twins whereas Bolton et al., Jorde et al., and Szatmari and Jones found rates of 2.9$3.7 \%$ among siblings. However, these findings all stress the importance of neurobiological investigation with regard to the development and expression of autistic disorder.

Although there is general agreement on the clinical features which define autism, aspects of the disorder's presentation pose obstacles for scientific study. First, there is a tremendous range of syndrome expression across individuals according to age or developmental level (Volkmar, 2001). This heterogeneity of syndrome expression can create difficulties in accurately diagnosing autism, particularly among the youngest and lowest-functioning individuals (Lord, 1995; Volkmar \& Lord, 1998). In particular, some children may exhibit the characteristic impaired social interest in the first few years of life but may not exhibit the unusual stereotyped behaviors and resistance to change until the following year or two (Lord, 1995). These same issues of symptom emergence are also found when attempting to diagnose profoundly retarded individuals, whose limited functional level makes detection of some of the features of autism difficult.

Another obstacle to the study of autism involves the comorbidity of individuals with autism (Volkmar \& Lord, 1998). Often, people with autism not only present with the classic features of the disorder, but also with associated behavioral problems such as hyperactivity, attentional difficulties, perseveration, self-injury, and aggression. Currently, there is a tension between the two official diagnostic systems; the Diagnostic and Statistical Manual of Mental Disorders (4th ed. [DSM-IV]; American Psychiatric Association, 1994), which tends to focus on symptoms, as opposed to the International Classification of Diseases-10th edition (World Health Organization, 1994), which tends to focus on the single, all-encompassing syndrome (Angold, Costello, \& Erkanli, 1999). These issues become particularly relevant when working with higher-functioning individuals with autism, in whom features of many different psychiatric conditions may be exhibited (Volkmar, 2001). Whether or not associated behavioral difficulties should be considered part of the syndrome of autism complicates an already clinically complex diagnostic issue.

This diagnostic uncertainty created by developmental level and comorbidity can pose considerable problems when trying to delineate the neurochemical features that comprise autistic disorder. Of course, the main goal of neurobiological research has been to reveal an all-encompassing etiology of autism that could account for the social, cognitive, and communication deficits that define the disorder. However, given the range of syndrome expression found within the diagnosis, it is hoped that certain biological measures may also have future diagnostic or prognostic utility.

This review seeks to investigate the current findings with regard to the neurochemical correlates of autism. While research has also examined other neurobiological aspects of the disorder (e.g., neuroanatomical), this article will be restricted to the chemical investigations in persons with autism. Neurochemical investigations of other neurobiological disorders (e.g., Parkinson's disease, schizophrenia) have helped to shape etiological theories and guide future pharmacologic interventions. In some cases, research in neurochemistry has completely elucidated the cause of neurological disorders, as is the case with phenylketonuria (PKU). In this condition, the devastating 
course of the disorder can be largely avoided by keeping phenylalanine out of the diet.

To date, neurochemical investigation has been most influenced by observed clinical responses to pharmacologic treatments; for example, the "dopamine hypothesis" of schizophrenia emerged from the significant improvements observed in schizophrenic patients who were receiving dopamine-blocking agents. Comparatively, research in the neurochemistry of autism has been somewhat less successful thus far, as there have been no known agents that can help to treat the core features of the disorder. Investigation into a wide array of chemical systems, including the monoamines, various neuropeptides, stress hormones, and amino acid neurotransmitters have been conducted, often with conflicting results. This review summarizes these investigations, and attempts to point out some of the more promising areas for future research.

\section{Serotonin}

Among all neurochemical investigations in autism, serotonin (5-hydroxytrypamine or 5-HT) has stimulated the most research and investigation. Serotonin is an indolamine that is derived from the essential amino acid tryptophan. Tryptophan is hydroxylated by tryptophan hydroxylase to create 5-hydroxytryptophan (5-HTP); this is the rate-limiting step in the synthesis of serotonin. Under normal physiological conditions, this enzyme is not fully saturated; therefore, increases in dietary tryptophan will usually result in increased levels of serotonin (Marsden, 1981). After tryptophan is converted into 5-HTP, it is finally decarboxylated (by 5-HTP decarboxylase) into serotonin.

Centrally, the cell bodies of serotonergic neurons are found in nine clusters, most of which are located in the raphe nuclei of the midbrain, pons, and medulla (Carlson, 2001). The two most important clusters with regard to behavior are found in the dorsal and medial raphe nuclei, both of which send projections to the cerebral cortex (Carlson, 2001; Marsden, 1981). The dorsal raphe nucleus also sends neuronal projections to the basal ganglia, an area of the brain important for the regulation of motor performance. The median raphe nucleus innervates the dentate gyrus, a part of the hippocampal formation (which is implicated in the storage of memory) (Carlson, 2001).

The behavioral effects of serotonin (5-HT) are complex. It regulates mood, eating, body temperature, and arousal, and it modulates pain sensitivity, sexual behavior, and hormone release. Initially, interest in 5-HT in autism arose from a consideration of its role in perception (Bauman \& Kemper, 1994). The powerful effects of serotonergic hallucinogens, such as lysergic acid diethyamide (LSD), provided the impetus for early studies of 5-HT in autism. Further evidence for a role of serotonin in the expression of autistic disorder was provided by the finding that acute depletion of dietary tryptophan (the dietary precursor of serotonin) led to worsening of autistic symptomatology (McDougle, Naylor, Cohen, Aghajanian, et al., 1996a; McDougle, Naylor, Cohen, Volkmar, et al., 1996b).

More recently, serotonin's role in early neural development has also been investigated as a possible etiological factor in the development of autistic disorder (Whitaker-Azimitia, 2001). Before assuming its role as a neurotransmitter in a mature brain, serotonin regulates both the development of serotonergic neurons as well as the development of target tissues, such as the hippocampus and the cerebral cortex. Whitaker-Azimitia (2001) suggested that high levels of serotonin during early development may cause a loss of serotonin terminals and subsequent neuronal development. Interestingly, researchers have shown that higher rates of autistic disorder occur in children who were exposed in utero to drugs known to increase serotonin levels, including cocaine (Davis et al., 1992; Kramer, Azmita, \& Whitaker-Azmita, 1994) and possibly alcohol (Nanson, 1992).

These findings have provided the impetus for investigation of serotonergic abnormalities 
in autistic disorder. Research has examined serotonergic functioning in the blood, cerebrospinal fluid, and, more recently, through the use of PET scans and genetic techniques.

\subsection{Blood 5-HT}

Early studies of blood serotonin in autism consistently found hyperserotonemia in one-third of people with autism; this has been replicated in more than 25 published studies (e.g., Shain \& Freedman, 1961; Ritvo et al., 1970; Campbell et al., 1975; Takahashi, Kanai, \& Miyamoto, 1976; McBride et al., 1998). The magnitude of this elevation is usually expressed as 5-HT in whole blood, and has typically been about 50\% above normal levels (McBride et al., 1998). Subsequent research has established that more than $99 \%$ of whole blood serotonin is contained in the platelets (Anderson et al., 1987) and that platelet serotonin accounts for the hyperserotonemia in autism (Cook, Leventhal, \& Freedman, 1988).

Animal research has indicated that hyperserotonemia can reduce the drive for social attachment by inhibiting separation distress (Chamberlain \& Herman, 1990); this could perhaps account for the deficits in social relatedness found in individuals with autism. However, the cause and significance of these elevated levels of blood serotonin in autism remain unclear. One might assume that hyperserotonemia, because it is an abnormal finding, would serve as a marker for impairment or dysfunction. However, two studies have failed to show the expected inverse relationship between blood 5-HT and verbal expressive ability (Cook et al., 1990; Cuccaro, Wright, Abramson, Marsteller, \& Valentine, 1993) in individuals with autism, so it is unknown how hyperserotonemia could play a role in autism's expression.

In addition, it is difficult to draw conclusions about what these peripheral measurements tell us about the central differences in autism; nearly all of the 5-HT found in the blood is manufactured in the gut prior to absorption by platelets. Hyperserotonemia is not found exclusively in autism; it is also found in a variety of medical and neuropsychiatric disorders such as schizophrenia (Freedman, Belendiuk, Belendiuk, \& Crayton, 1981), Huntington's disease (Belendiuk, Belendiuk, \& Freedman, 1980), and severe mental retardation (Hanley, Stahl, \& Freedman, 1977; Pare, Sandler, \& Stacey, 1960; Partington, Tu, \& Wong, 1973). It is notable that the children first reported as having elevated blood serotonin in Shain and Freedman's (1961) landmark paper were diagnosed not only with autistic disorder, but with severe mental retardation as well. It is likely that most reports of blood 5-HT are complicated by factors beyond the diagnosis of autistic disorder.

In an attempt to elucidate some of these variables, McBride et al. (1998) examined the effects of diagnosis (autistic versus mentally retarded versus typically developing), race, and puberty on blood levels of serotonin. They found among prepubertal children only, significant effects of diagnosis (with subjects with autism having higher 5-HT levels) and race (with white children having lower 5-HT levels than black or Latino youngsters, regardless of diagnosis). While these findings confirm that hyperserotonemia is more prevalent in children with autism, McBride et al. also stressed the importance of matching for pubertal status and race when conducting neurochemical research. It is possible that the hyperserotonemia reported in individuals with autism may have been overestimated due to failure to control for subject variables (McBride et al., 1998). Clearly, the study of whole blood serotonin is a complex issue; it is present in a variety of neurological disturbances, and it yields very little information about central serotonergic functioning. Therefore, it alone may not shed any light on the specific etiological mechanisms that are exclusive to autistic disorder.

\subsection{CSF 5-HIAA}


To assess central serotonergic functioning in autism, seven studies examined levels of 5-hydroxyindoleacetic acid (5-HIAA; serotonin's major metabolite) in cerebral spinal fluid (CSF). Because nearly all 5-HT in the brain is metabolized to 5-HIAA before elimination, measurement of 5-HIAA in CSF provides a relatively accurate measure of central levels of serotonin, as it has been shown that it is not contaminated with 5-HT or 5-HIAA that is found elsewhere in the body (Anderson \& Hoshino, 1997). The seven studies (Cohen, Shaywitz, Johnson, \& Bowers, 1974; Cohen, Caparulo, Shaywitz, \& Bowers, 1977; Winsberg, Sverd, Castells, Hurwic, \& Perel, 1980; Gillberg, Svennerholm, \& Hamilton-Helberg, 1983; Ross, Klykylo, \& Anderson, 1985; Narayan, Srinath, Anderson, \& Meundi, 1992) we were able to locate are summarized in Table 1.

Researchers have theorized that central serotonergic functioning is depressed in individuals with autism, as supported by the efficacy of serotonin reuptake inhibitors (SSRIs) in treating rituals and aggression in autism, at least in adults with autism (Cook, Rowlett, Jaselskis, \& Leventhal, 1992; Gordon, State, Nelson, Hamburger, \& Rapoport, 1993; McDougle et al., 1996a,b), as well as the finding that acute tryptophan depletion caused worsening of autistic symptomatology (McDougle et al., 1996a,b). However, the seven reports of measurements of 5-HIAA in CSF were consistent in showing no differences between autistic and control groups. These findings suggest that if there is a central serotonergic abnormality in autism, it does not involve a widespread or marked change in the turnover of 5-HT (Anderson, 1994).

\subsection{Positron emission tomography (PET) studies}

Recently, $\alpha$ - $\left[{ }^{11} \mathrm{C}\right]$ methyl-L-tryptophan $\left(\left[{ }^{11} \mathrm{C}\right] \mathrm{AMT}\right)$ has been developed as a tracer for measuring serotonin synthesis in the brain, using positron emission tomography (PET). PET allows one to observe the regional variance in serotonin synthesis and thus is a much more precise and informative measure of central serotonergic functioning in autism. To date, there have been two published studies using this method in subjects with autism. The first, conducted by Chugani et al. (1997) measured 5-HT synthesis in eight children with autism (seven boys, one girl: mean age 6.6 years) and five of their siblings (four boys, one girl; mean age 9.9 years). A diagnosis of autism was made using DSM-IV criteria, as well as meeting the criteria for autism using the Gilliam Autism Rating Scale (GARS) and the Childhood Autism Rating Scale (CARS).

Examination of the PET images revealed clear differences between the boys with autism and their siblings. In boys with autism, unilateral decreased 5-HT synthesis was found in the frontal cortex and thalamus and increased levels were found in the contralateral dentate nucleus of the cerebellum. For five of the seven boys, decreased accumulation was seen in the left frontal cortex and thalamus, accompanied by elevated accumulation on the right dentate nucleus. The remaining two boys had the mirror opposite image pattern of abnormality, with decreased accumulation seen in the right frontal cortex and thalamus with increased accumulation seen on the left dentate nucleus. This "reversed" pattern was not related to handedness or any other obvious subject characteristic. The frontal cortex, thalamus, and dentate nucleus are all connected via the dentatothalamocortical pathway, which is involved in sensory integration and speech production - skills that are significantly impaired in individuals with autistic disorder. In addition, the finding that 5-HT synthesis is elevated in one area and lowered in another could explain why measurements of 5-HIAA in CSF (discussed previously) have not shown any overall mean differences, as these differences in regional serotonin synthesis could in essence cancel one another out (Chugani et al., 1997).

A subsequent study by Chugani et al. (1999) examined the effects of age on serotonin synthesis in autistic and typically-developing subjects. This study had a larger sample size, 


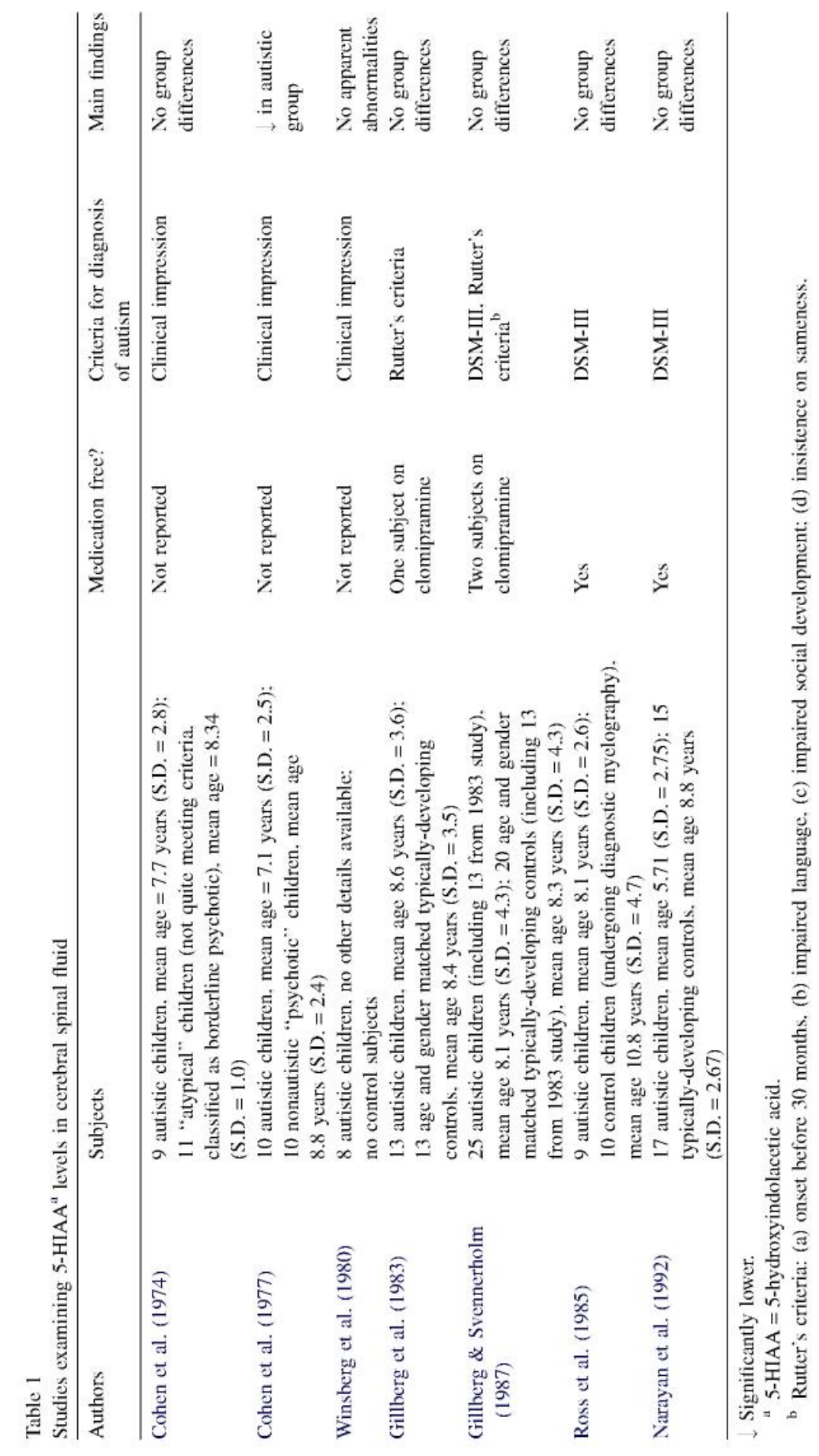


involving 30 subjects with autism ( 24 boys, 6 girls, age range of 2.3-15.4 years), 8 of their siblings (6 boys, 2 girls, age range of 2.1-14.4 years), and 16 children with epilepsy ( 9 boys, 7 girls, age range 3 months to 13.4 years). A diagnosis of autism was rigorously fulfilled using DSM-IV criteria, as well as meeting criteria from the GARS, CARS, and the Autism Diagnostic Interview-Revised (ADI-R; Lord, Rutter, \& Le Couteur, 1994). Examination of the PET images revealed that children without autism between the ages of 2 and 5 years showed high levels of 5-HT synthesis, which subsequently declined towards adult values between the ages of 5 and 14 years. Children with autism, on the other hand, did not show this decline in serotonin synthesis capacity over time; in fact, levels were significantly lower in these children at age 2-5 compared to controls and increased slightly with age (observed in both male and female subjects). This suggests that developmental regulation of serotonin synthesis may be involved in the pathogenesis of autism. As in the previous study, focal abnormalities were noted in boys with autism regardless of age, with increased serotonin synthesis seen in the frontal cortex and thalamus. The subjects with epilepsy also showed focal regions of increased 5-HT synthesis that were associated with the foci of their epilepsy. Focal differences were not observed in girls with autism, which could be due in part to gender differences in hemispheric specialization, but this requires further study.

\subsection{Genetic studies}

Motivated by the evidence for a genetic basis of autism (as evidenced by sibling and twin studies), researchers have begun to investigate potential candidate genes for the development and expression of autism. Some of this research has focused on the serotonin transporter gene (SLC6A4), which encodes for both the platelet and neuronal transport of 5-HT. Interest in this gene can be attributed to its possible role in the platelet hyperserotonemia in autism and to the clinical utility of SSRIs (which target these transporter proteins).

Two polymorphisms have been reported for SLC6A4: the deletion or short (s) allele and the long ( $l$ ) alelle (Tordjman et al., 2001). These polymorphisms are functionally significant; cell lines with sl or ss genotypes are shown to have approximately one-half the rates of 5-HT transport when compared to cell lines with $I l$ genotypes (Lesch, Wolozin, Murphy, \& Riederer, 1993). Theoretically, an "overactive"' serotonin transporter (e.g., one with a ll genotype) would take 5-HT out of the synaptic cleft too quickly, causing a relative deficiency. This would be in line with the idea that areas of central serotonergic functioning are depressed in individuals with autism.

We located six studies examining polymorphisms of this gene in autism (Cook et al., 1997; Klauck, Poutska, Benner, Lesch, \& Poutska, 1997; Maestrini et al., 1999; Persico et al., 2000; Tordjman et al., 2001; Yirmiya et al., 2001), and these are summarized in Table 2. Results do not provide clear evidence for consistent genotypic characteristics of people with autism: three studies failed to show any association of either polymorphism to autism, two studies showed preferential transmission of the long polymorphism, and one study showed preferential transmission for the short polymorphism.

At this point, it is difficult to determine the role of the serotonin transporter gene in autism. It is likely that autism will be characterized by genetic heterogeneity, and as is the 


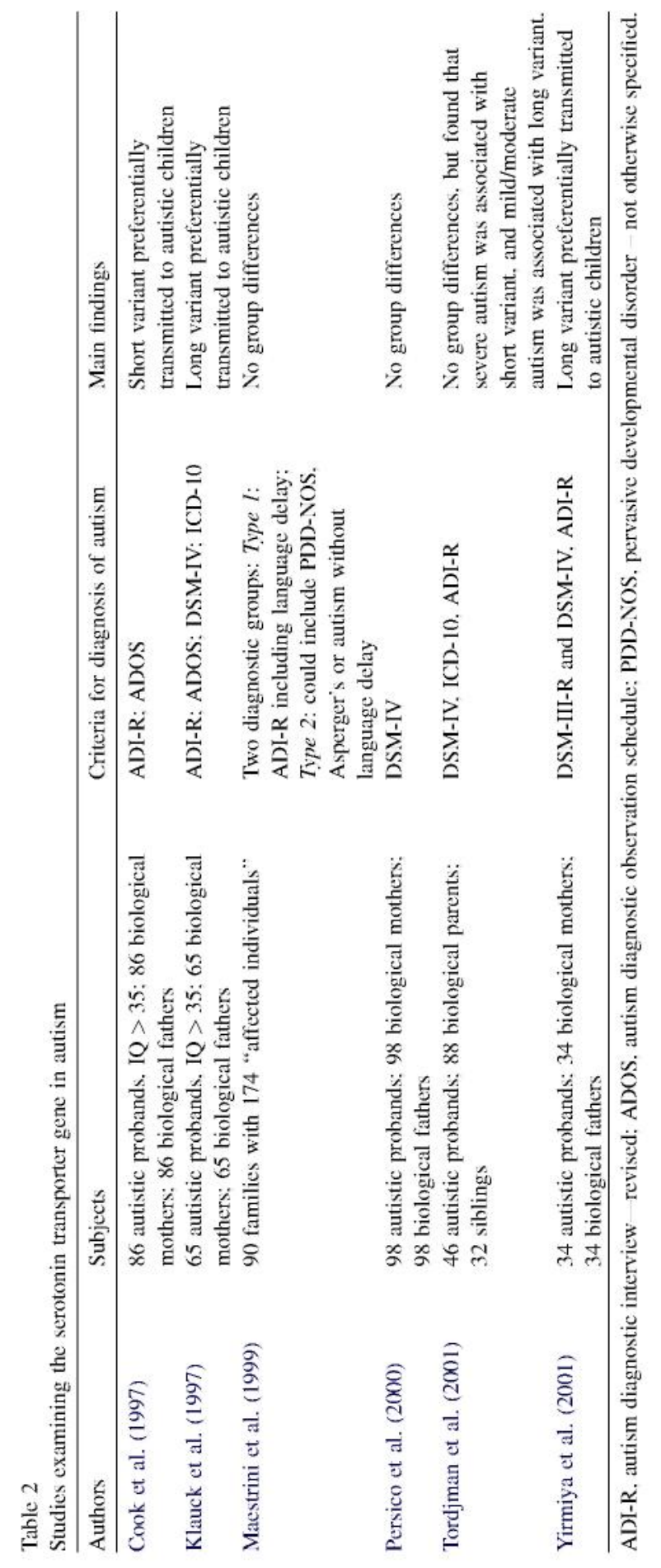


case with many complex conditions, one gene may not be necessary or sufficient to produce the disorder (Yirmiya et al., 2001). Genetic heterogeneity would be consistent with the clinical heterogeneity in autism noted earlier. It is then notable that in one of the studies, while failing to find that any specific genotype conveyed risk for developing autistic disorder, the investigators found that the severity of autism was impacted by genotype, with greater $l$ transmission being observed in mild/moderate cases of autism and greater $s$ transmission observed in more severely impaired individuals (Tordjman et al., 2001). It is possible that while the serotonin transporter gene may not serve as a clear marker for autism, it may influence its behavioral phenotypic expression. Clearly, the study of serotonin in autism is a complex issue, and more research is needed in order to elucidate its possible role in autistic disorder.

\subsection{Clinical/treatment implications}

These potential abnormalities in serotonergic function naturally lead to hypotheses about treatment possibilities, and a number of strategies have been tried. Researchers have conducted investigations of L-Dopa and numerous studies of fenfluramine (both lower blood serotonin, presumably by relieving serotonergic-deficit up-regulation of serotonin production) in individuals with autism in hopes of producing clinical improvement. These studies failed to show consistent significant clinical benefit (Aman \& Kern, 1989; Campbell, Anderson, \& Small, 1990).

A large number of investigators have shown interest in the selective serotonin reuptake inhibitors (SSRIs; e.g., fluoxetine, paroxetine, citalopram) for various reasons. Beyond the "serotonin hypothesis" discussed above, these agents are also known to be effective as antidepressants and as effective anti-OCD (obsessive compulsive disorder) agents. The presence of restricted repetitive behavior in individuals with autism may justify the use of these medications for some practitioners. In fact, recent surveys of medication use in autism have reported that SSRIs are the most commonly-prescribed psychotropic medication in autism (Langworthy-Lam, Aman, \& Van Bourgondien, 2002; Aman, Lam, \& Collier-Crespin, 2003). Aman, Arnold, and Armstrong (1999) reviewed 47 case reports and studies of SSRIs and clomipramine, a serotonergic tricyclic antidepressant, in subjects with developmental disabilities (including autism). A large majority - but not all — of these reports suggested that these agents were often effective in managing perseverative behavior, including compulsions, stereotypies, and self injury (Aman et al., 1999). Further controlled research is needed, especially in pediatric samples, as it is possible that SSRIs may have different effects in younger people with autism. These differential effects may be related to the developmental variations in serotonin levels described above.

The atypical antipsychotics can be characterized as dopamine and serotonin receptor blockers. Although discussion of antipsychotics belongs more properly in the next major section, they deserve brief mention here. Recently, the Research Units on Pediatric Psychopharmacology (RUPP) Autism Network (2002) assessed risperidone in a double blind, placebo controlled trial in 101 children chosen for high levels of irritability. Risperidone had a variety of therapeutic effects on both comorbid irritable behaviors and stereotypic/compulsive behavior.

\section{Dopamine}

Dopamine (DA) is a catecholamine that is synthesized from the dietary amino acid tyrosine. Once ingested, tyrosine is hydroxylated (by tyrosine hydroxylase) into L-dihydroxyphenylalanine (L-DOPA). This is the rate-limiting step of the synthesis of dopamine.

L-DOPA is then converted to dopamine via the enzyme DOPA decarboxylase. Most DA-containing neurons lie in the midbrain; in particular, three important DA systems project from the substantia 
nigra and the ventral tegmental area (Carlson, 2001). The nigrostriatal system has cell bodies located in the substantia nigra that project their axons to the neostriatum, an area that is involved in the control of movement. The mesolimbic system contains cell bodies in the ventral tegmental area and projects axons to several parts of the limbic system, including the nucleus accumbens (which plays a role in the reinforcing effects of certain stimuli), the amygdala (involved in emotion) and the hippocampus (involved in memory). Lastly, the mesocortical system also has its cell bodies in the ventral tegmental area; its axons, however, project to the prefrontal cortex, an area critical for higher-order functions, such as planning and formation of short-term memories (Carlson, 2001).

In general, the dopaminergic system is thought to affect a wide range of behaviors and functions, including cognition, motor function, brain-stimulation reward mechanisms, eating and drinking behaviors, sexual behavior, neuroendocrine regulation, and selective attention (Calne, Chase, \& Barbeau, 1975; Costa \& Gessa, 1977; Roberts, Woodruff, \& Iversen, 1978). Interest in the role of DA in autism began with the observation that some DA blockers (i.e., antipsychotics) have been observed to be effective in treating some aspects of autism (Anderson \& Hoshino, 1997). Specifically, the antipsychotics appear to alleviate hyperactivity, stereotypies, aggression, and self-injury (Young, Kavanagh, Anderson, Shaywitz, \& Cohen, 1982). In addition, animal research has shown that stereotypies and hyperactivity can be induced by increasing dopaminergic functioning. These observations suggested that dopaminergic neurons could be overactive in autism, which led to studies of DA function. These were done by several methods, including blood and urine measurements of DA and its major metabolite, and measurements of this metabolite in CSF.

\subsection{Blood and urine}

Once released from the neuron, central DA is broken down into homovanillic acid (HVA) and 3,4-dihydroxyphenylacetic acid (DOPAC). These substances, as well as DA itself, can be measured in both blood and urine. Measurements of urinary excretion of DA and HVA in autism have been essentially equivocal. Although some researchers have reported increased levels in autism (see Anderson \& Hoshino, 1997 for a review), in a large study of autistic versus control subjects, no differences were found (Minderaa et al., 1989). In the one study that examined plasma levels of DA metabolite, no differences between autistic and control subjects were found (Minderaa et al., 1989). At this point, there does not appear to be any evidence of peripheral dopaminergic abnormalities of autism; in addition, it is not clear how these peripheral measurements relate to central dopaminergic functioning (Anderson \& Hoshino, 1997). It has been suggested that only about $25 \%$ of blood or urine HVA is of central origin (Elchiasak, Polinsky, Ebert, Powers, \& Kopin, 1978; Maas, Hattox, Greene, \& Landis, 1980). Therefore, these measurements would only be capable of detecting widespread or marked alterations in the metabolism of DA in the brain (Anderson, 1994).

\subsection{CSF HVA}

In order to assess central dopaminergic functioning, measures of CSF HVA have been conducted. A total of seven studies in individuals with autism were located (Cohen et al., 1974, 1977; Winsberg et al., 1980; Gillberg et al., 1983; Gillberg \& Svennerholm, 1987; Ross et al., 1985; Narayan et al., 1992) and are described in Table 3. In two of these studies (Gillberg et al., 1983; Gillberg \& Svennerholm, 1987) approximately $50 \%$ of subjects with autism exhibited significantly elevated levels of CSF HVA. The remaining five studies showed no significant mean differences between control subjects and subjects with autism. 
However, in the Cohen et al. studies $(1974,1977)$, though no significant group differences were found, the children with autism who displayed greater hyperkinesis and more severe stereotypies tended to have higher CSF HVA levels. These findings are similar to those found in studies examining symptom severity in Tourette's disorder, where higher CSF HVA levels were correlated with more severe tics (Cohen et al., 1978). In addition, it has been found that CSF HVA levels are generally higher in males than in females (Leckman et al., 1980). Perhaps the higher CSF HVA levels in autism could be due in part to the markedly higher prevalence of the disorder in males (Young et al., 1982). At this point, whether or not central DA turnover is increased in autism is still a subject of debate (Gillberg, 1993; Narayan et al., 1992). These studies do not provide strong support for increased CSF HVA levels in autism. Taken together with the blood and urine studies, there is little evidence for differences between autistic and control subjects in neurochemical indexes in DA functioning.

\subsection{Clinical/treatment implications}

The more positive findings above led to early trials of dopamine-blocking agents, notably classical antipsychotic drugs, as possible treatment for core autistic symptoms. Some success has been demonstrated for repetitive, stereotyped behaviors, which, of all autistic symptoms, seem most closely linked theoretically with excess dopamine transmission (Schroeder, 1988; Ernst et al., 1999). Hyperactivity and aggression also were sometimes improved.

In the RUPP Autism Network (2002) study mentioned previously, treatment with risperidone caused reductions on all subscales of the Aberrant Behavior Checklist (Aman \& Singh, 1994), with large reductions occurring on the Irritability, Stereotypic Behavior, and Hyperactivity subscales. Smaller, marginally-significant, effects were also observed on the Lethargy/Social Withdrawal and Inappropriate Speech (often manifested as echolalia) subscales. It is not clear whether risperidone truly influenced core symptoms or whether the changes seen in these core manifestations were a "halo" effect of major symptom reduction in acting out symptoms. McDougle et al. (in press) reported on other ("secondary") measures from the RUPP study. They reported significant drug-related 


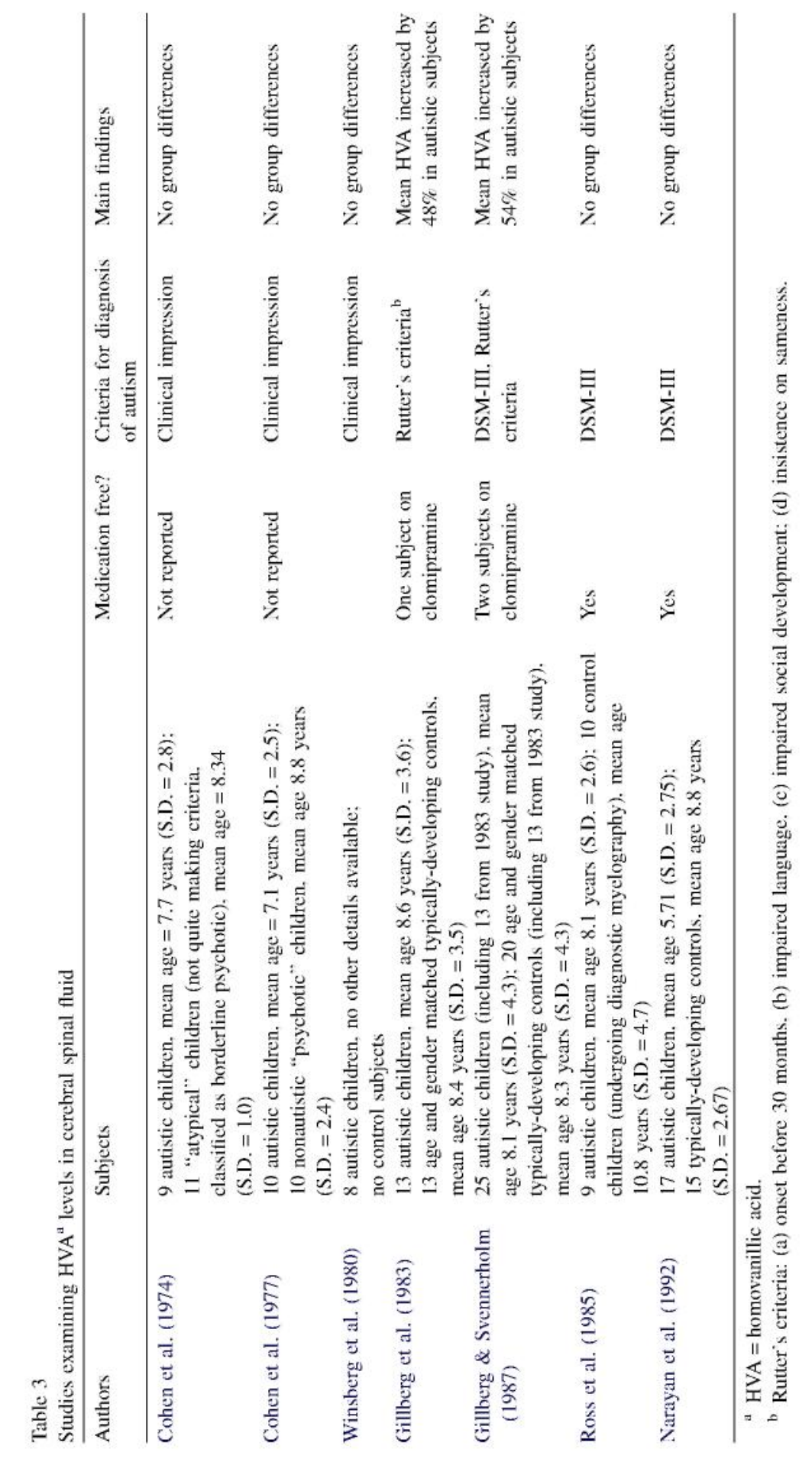


improvements in restricted, repetitive, and stereotyped patterns of behavior but not in social interactions and communication. At this stage, it is not clear whether longer exposure to risperidone or other atypical antipsychotics may produce lasting changes in core manifestations of autism.

\section{Norepinephrine}

Norepinephrine (also known as noradrenaline) is a catecholamine that is synthesized from DA through the action of the enzyme DA beta-hydroxylase. Nearly every region of the brain receives input from noradrenergic neurons (Carlson, 2001). The cell bodies of the most important system are located in the locus coeruleus, which is located in the dorsal pons. The projections of this area are distributed widely throughout the brain, and activity of these systems is thought to play a critical role in attention, filtering of irrelevant stimuli, stress response (e.g., "fight or flight" response), anxiety, and memory (Amaral \& Sinnamon, 1977; Moore \& Bloom, 1979). Since many of these functions are impaired in individuals with autism, researchers have investigated whether noradrenergic functioning within the diagnosis is altered. Noradrenergic activity has been assessed in autism via measurement of norepinephrine (NE) and its central and/or peripheral metabolites in blood, urine, and CSF.

\subsection{Blood studies}

Noradrenergic function can be measured in the blood as NE itself, and as its principal central metabolite, 3-methoxy-4-hydroxyphenylglycol (MHPG). Unlike some of the other neurotransmitter systems, central and peripheral noradrenergic systems are tightly coupled (Schildkraut et al., 1978) with blood and CSF concentrations being highly correlated (Raskind, Peskind, Halter, \& Jimerson, 1984; Roy, Pickar, DeJong, Karoum, \& Linnoila, 1988; Ziegler, Wood, Lake, \& Kopin, 1977). As a result, peripheral measurements may give a good perspective on central noradrenergic functioning. A total of seven studies examining NE system levels in the blood were located; these are listed in Table 4. Five of these, all of which measured NE, showed higher concentrations in subjects with autism as compared with controls (Lake, Ziegler, \& Murphy, 1977; Launay et al., 1987; Cook et al., 1990; Leventhal, Cook, Morford, Raviatz, \& Freedman, 1990; Leboyer, Bouvard, \& Launay, 1992). The results of the remaining two studies, which measured MHPG levels, failed to show any differences between individuals with autism and normal controls (Young et al., 1981; Minderaa, Anderson, Volkmar, Akkerhuis, \& Cohen, 1994).

\subsection{Urine studies}

Studies examining excretion of NE and its metabolites in individuals with autism have yielded inconsistent findings. When analyzing excretion rates of norepinephrine, researchers have found increased (Barthelemy et al., 1988), decreased (Young, Cohen, Brown, \& Caparulo, 1978), as well as equivocal (Launay et al., 1987; Martineau,

\begin{tabular}{|c|c|c|c|c|}
\hline Authors & Subjects & Medication free? & $\begin{array}{l}\text { Criteria for } \\
\text { diagnosis of } \\
\text { autism }\end{array}$ & Main findings \\
\hline
\end{tabular}

Plasma Norepinephrine 


\begin{tabular}{|c|c|c|c|c|}
\hline Lake et al (1977). & $\begin{array}{l}11 \text { autistic children, mean } \\
\text { age } 15 \text { years }(\text { S.D. }=2.0) \text {; } \\
12 \text { typically-developing } \\
\text { controls, matched for age, } \\
\text { mean age } 15 \text { years (S.D. = } \\
1.0 \text { ) }\end{array}$ & No & $\begin{array}{l}\text { Kanner's } \\
\text { Criteria }\end{array}$ & $\begin{array}{l}\uparrow \text { In autistic } \\
\text { subjects }\end{array}$ \\
\hline $\begin{array}{l}\text { Launay et al. } \\
\text { (1987) }\end{array}$ & $\begin{array}{l}22 \text { autistic children, mean } \\
\text { age } 10.5 ; 22 \text { typically } \\
\text { developing controls, } \\
\text { matched for age and sex }\end{array}$ & $\begin{array}{l}\text { Two subjects on meds: } \\
\text { thioridazine and } \\
\text { pericytazine, tested in } \\
\text { vitro to have no effect on } \\
\text { NE }\end{array}$ & DSM III & $\begin{array}{l}\uparrow \text { In autistic } \\
\text { subjects }\end{array}$ \\
\hline $\begin{array}{c}\text { Conk et al. } \\
\text { (1990) }\end{array}$ & $\begin{array}{l}16 \text { autistic children; } 21 \\
\text { siblings of autistic } \\
\text { children; } 53 \text { parents of } \\
\text { autistic children }\end{array}$ & Not known & DSM III & $\begin{array}{l}\uparrow \text { In autistic } \\
\text { subjects, } \\
\text { especially in } \\
\text { those with } \\
\text { hyperserotonemi }\end{array}$ \\
\hline $\begin{array}{l}\text { Leventhal et al. } \\
\text { (1990) }\end{array}$ & $\begin{array}{l}39 \text { autistic children, mean } \\
\text { age } 8.99(\text { S.D. }=4.4) ; 32 \\
\text { siblings of autistic } \\
\text { children, mean age } 11.2 \\
\text { years (S.D. }=5.3) ; 78 \\
\text { parents of autistic children, } \\
\text { mean age } 38.7 \text { years (S.D. } \\
=6.5) ; 98 \text { unrelated adult } \\
\text { controls, mean age } 28.2 \\
\text { (S.D. }=8.4 \text { ) }\end{array}$ & Yes & DSM III & $\begin{array}{l}\uparrow \text { In autistic } \\
\text { subjects }\end{array}$ \\
\hline $\begin{array}{l}\text { Leboyer et al. } \\
\qquad(1992)\end{array}$ & $\begin{array}{l}\text { All subjects autistic with } \\
\text { severe MR and SIB: } 1 \\
\text { autistic female, aged } 12 \\
\text { years; } 3 \text { autistic males, } \\
\text { aged } 4 \text { years, } 12 \text { years, and } \\
19 \text { years }\end{array}$ & $\begin{array}{l}\text { One subject on a } \\
\text { neuroleptic }\end{array}$ & DSM III & $\begin{array}{l}\uparrow \text { In autistic } \\
\text { subjects }\end{array}$ \\
\hline \multicolumn{5}{|l|}{ Plasma $M H P G^{\mathrm{a}}$} \\
\hline Young et al. (1981) & $\begin{array}{l}10 \text { autistic subjects, mean } \\
\text { age } 10.6 \text { years (S.D. }=4.5 \text { ); } \\
15 \text { subjects with Tourette's } \\
\text { syndrome, mean age } 16.1 \\
\text { (S.D. }=11.1 \text { ); } 8 \text { typically } \\
\text { developing boys, mean age } \\
11.9 \text { years (S.D. }=10.6 \text { ) }\end{array}$ & No & DSM III & No difference \\
\hline $\begin{array}{l}\text { Minderaa et al. } \\
\text { (1994) }\end{array}$ & $\begin{array}{l}40 \text { autistic individuals, } \\
\text { mean age } 20.0 \text { years (S.D. } \\
=4.4) ; 20 \text { age- and } \\
\text { sex-matched typically } \\
\text { developing controls, mean } \\
\text { age } 19.6 \text { years (S.D. }=6.7 \text { ) }\end{array}$ & $\begin{array}{l}\text { No, but grouped } \\
\text { according to drug use; no } \\
\text { effect }\end{array}$ & DSM III & No difference \\
\hline
\end{tabular}

$\uparrow$ Significantly higher.

${ }^{\mathrm{a}} \mathrm{MHPG}=3$-methoxy-4-hydroxyphenylglycol (principal central metabolite of norepinephrine).

Table 4. Studies examining noradrenergic functioning

Barthelemy, Jouve, Muh, \& Lelord, 1992; Minderaa et al., 1994; Croonenberghs et al., 2000) 
concentrations in individuals with autism when compared to control subjects. Other studies looking at excretion rates of MHPG have reported decreased (Young et al., 1978; Barthelemy et al., 1988) and normal (Launay et al., 1987; Minderaa et al., 1994) activity in subjects with autism. Lastly, studies examining levels of norepinephrine's predominant peripheral metabolite, vanillylmandelic acid (VMA) did not produce significant differences between autistic and control subjects (Minderaa et al., 1994).

\subsection{Studies of CSF}

Two studies measuring levels of MHPG in cerebrospinal fluid were located (Young et al., 1981; Gillberg \& Svennerholm, 1987). Both of these studies used DSM-III criteria to diagnose autism, and neither study showed any significant difference between autistic and control subjects.

Overall, these results indicate that the only consistent abnormal finding with regard to noradrenergic functioning in autism is elevated plasma norepinephrine levels. All other measurements suggest that noradrenergic functioning is not greatly altered within the disorder. Initially, the elevated plasma NE may seem to be in conflict with all of these other null findings. However, when one considers the time frame of the various measures, these seemingly disparate findings may be reconciled. It is known that plasma NE has an extremely short half-life and largely reflects the state of sympathetic arousal at the time of blood drawing (Minderaa et al., 1994). The other measurements of blood, urine, and CSF are time-averaged indices of noradrenergic functioning. It is then possible that baseline NE functioning is normal in subjects with autism, but that clinical procedures (such as drawing blood) may lead to hyperarousal and a heightened sympathetic response (Minderaa et al., 1994; Cook, 1990), thus resulting in temporarily higher levels of NE in the blood. Collectively, these results suggest little role for NE in the expression and etiology of autistic disorder.

\subsection{Clinical/treatment implications}

Consistent with the paucity of findings above, benefit from norepinephrine agonists and antagonists in autism has been sparsely reported, inconsistent, and clouded with adverse events. Tricyclic antidepressants such as imipramine, desipramine, and nortriptyline are all norepinephrine reuptake blockers, although they have other actions, such as dopamine presynaptic reuptake blockade. Gordon et al. (1993) compared placebo, desipramine, and clomipramine in 24 subjects with autistic disorder. Both desipramine and clomipramine reduced hyperactivity, whereas clomipramine had additional effects on stereotypic, compulsive, and ritualistic behavior. Thus the adrenergic effect seemed to be confined to hyperactivity, whereas clomipramine's effect on perseverative behavior appears to be due to its serotonergic effects (discussed previously in the serotonin section). McDougle and Posey (2003) noted that alpha 2 agonists like clonidine and quanfacine, which dampen noradrenalin action, are sometimes helpful for managing hyperactivity in young people with autism. However, the drugs do not appear to affect any of the core manifestations of autism. Postsynaptic beta blockers, like propranolol and nadolol, are sometimes helpful for managing aggression, self injury, and agitation (Fraser, Ruedrich, Kerr, \& Levitas, 1998), but again they appear to have no consistent effect on manifestations of autism.

\section{Acetylcholine}

Acetylcholine (ACh) is the neurotransmitter found at the neuromuscular junction, in autonomic nervous system ganglia, and in multiple sites in the CNS (Kandel, Schwartz, \& Jessel, 1995). In the brain, three systems have been of interest to neuroscientists: the dorsolateral pons (involved in REM sleep), the basal forebrain (which activates areas of the cerebral cortex and 
facilitates learning), and the medial septum (which projects to the hippocampus, an area involved in memory). There are two kinds of ACh receptors: nicotinic and muscarinic. Both are found in the brain, though muscarinic receptors are more prevalent. Overall, the cholinergic system has been referred to as an "action system" that helps develop the ability to focus on the environment and achieve a coherent behavioral response (Stahl, 1996).

The role of acetylcholine deficits in autism has not been explored until recently. However, a report of neuropathological abnormalities in cholinergic neurons located in the basal forebrain of individuals with autism has generated interest in the study of acetylcholine (Bauman \& Kemper, 1994). Since the cholinergic system has been shown to play a role in the development and function of cognitive abilities, it has been hypothesized that a disruption in this system could be linked to the cognitive deficits that often accompany autism (e.g., problems with attention, learning). At this point, investigators have only begun to examine ACh function in autism, via postmortem studies of acetylcholine function and medication studies, which are summarized below.

\subsection{Postmortem studies}

A series of three studies examining cholinergic activity in autism postmortem were located (Perry et al., 2001; Lee et al., 2002; Martin-Ruiz et al., 2004). In the first of these studies, Perry et al. (2001) compared the brains of individuals with autism to the brains of individuals with mental retardation, as well as to the brains of typically-developing individuals matched for age. Measures of cholinergic enzyme markers (acetylcholinetransferase and acetylcholinesterase) showed no significant differences between groups. However, analysis of receptor binding revealed a large (65-75\%) and significant reduction in ACh binding in nicotinic (alpha 4 and beta 2) receptors in the parietal and frontal cortexes in autism. Significant reductions (30\%) in muscarinic (M1) receptors in the parietal cortex were also found in individuals with autism. Subsequent research has assessed further potential abnormalities of nicotinic receptors in autism (Lee et al., 2002; Martin-Ruiz et al., 2004). However, it is unclear how these differences might be related to the etiology of autism. It has been suggested that the findings of decreased nicotinic receptor function may provide a cue for possible medication interventions, as nicotinic receptor agonists are known to enhance attentional function (Lee et al., 2002).

\subsection{Clinical/treatment implications}

At this stage, the best strategy for boosting the action of $\mathrm{ACh}$ in the brain is to inhibit agents that metabolize ACh. Several drugs have been developed to fight the brain-wasting that occurs with Alzheimer's disorder. They work to increase central ACh activity by leaving it in the synaptic cleft longer before it is broken down by enzymes. Researchers have begun to investigate the use of acetylcholinesterase inhibitors, including donezepil (Chez, Tremb, Nowinski, \& Field-Chez, 2001; Hardan \& Handen, 2002), galantamine (Niederhofer, Staffen, \& Mair, 2002), and rivastigmine tartate (Chez, Aimonovitch, Buchanan, Mrazek, \& Tremb, 2004) in autism. Two of these investigations were double-blind, placebo-controlled studies, and both reported improvements with active treatment (Niederhofer et al., 2002; Chez et al., 2001). Niederhofer et al. reported improvements in irritability, whereas Chez et al. (2001) reported improvements in symptoms of autism and in language. Hardan and Handen (2002) treated eight patients having autism with donepezil in an open trial. Four of them were regarded as showing substantial improvement, with behavioral changes largely occurring in the areas of irritability and hyperactivity. These results provide preliminary evidence for the use of acetylcholinesterase inhibitors in autism, and they suggest that further study of the cholinergic system in autism is warranted. 


\section{Oxytocin}

Oxytocin (OT) is a peptide synthesized in the paraventricular nucleus (PVN) and the supraoptic nucleus (SON) in the brain. Cells in the PVN that synthesize oxytocin project diffusely throughout the brain and the brainstem (Sofroniew \& Weindl, 1981). It has also been found that receptors for oxytocin are located throughout the limbic system in the forebrain and in the autonomic centers in the brainstem (Barberis \& Tribollet, 1996). These observations strongly suggest that OT acts centrally as a neuromodulator (Insel, O’Brien, \& Leckman, 1999).

Behaviorally, the OT system has been implicated in maternal behavior, infant separation distress, sexual behavior, and in the development of social attachments (Insel et al., 1999; Insel, 1992). Animal research has provided much of the groundwork for these findings; for example, in monogamous prairie voles, oxytocin was shown to be both necessary and sufficient for the normal development of partner selection in females (Insel \& Hulihan, 1995). If an oxytocin antagonist is administered to these species, pair bonding will not occur. Conversely, if oxytocin is administered centrally, pair bonding is facilitated, even in the absence of mating.

Given that social impairment is a primary symptom of autistic disorder, researchers have begun to investigate whether or not the OT system is dysfunctional in individuals with autism. However, research in this area is in its infancy. To date, there has been one study examining blood levels of oxytocin (Modahl et al., 1998). A total of 29 boys with autism and 30 controls between the ages of 6 and 11 were studied; this involved a blood draw, as well as a series of social and developmental measures. As a group, subjects with autism had significantly lower levels of oxytocin. Moreover, when the relationships of OT to subject characteristics were examined, two interesting trends emerged.

First, OT plasma levels were positively associated with age for normal children, but not for children with autism. The rise in OT in older children is consistent with the surge of other hormone systems that increase before the onset of puberty in normal children (Modahl et al., 1998). The lack of an increase in OT in children with autism may reflect delay in physical maturation in this group (Campbell et al., 1980; Simon \& Gillies, 1976) or a failure of the trigger for developmental increase in OT. Second, and perhaps more interestingly, in normal children oxytocin levels were positively related to socialization skills. However, oxytocin levels were negatively related to socialization skills in children with autism (Modahl et al., 1998). This finding suggests that a simple OT deficit model in autism is not adequate. Rather, these lower blood oxytocin levels may reflect compensatory mechanisms for underlying abnormalities in receptors or substances upstream from OT, resulting in secondary dysregulation (Modahl et al., 1998). These studies can be viewed as preliminary suggestive evidence that oxytocin dysregulation may play a role in the disorder.

\subsection{Clinical/treatment implications}

The intriguing findings above raise hope of finding some neurochemical treatment that might directly address the social impairment of autism, which, in contrast to stereotyped behavior, has generally been resistant to psychopharmacology. Recently, data were presented from a study in which 15 adults with autism or Asperger's disorder were infused with either synthetic OT (pitocin) or placebo in a double-blind crossover fashion (Hollander et al., 2003). Administration of oxytocin resulted in significant decreases in repetitive behaviors in subjects with autism. Social impairment was not assessed. More investigation of this hormone would be helpful in determining if it has a therapeutic role to play. Unfortunately, synthetic OT (pitocin) is only available in an injectable vehicle, which impedes efforts to assess what its effects may be in more real-life settings. Furthermore, having administration confined to injections would seriously limit the practical 
utility of most agents with short times of action.

\section{Endogenous opioids}

Endogenous opioids are peptides that exert effects on the central nervous system, acting as neuromodulators. There are three distinct types: beta-endorphins, enkephalins, and dynorphin. Each type of opioid has a different affinity for a certain receptor subtype: beta-endorphins for mu receptors (implicated in analgesia and euphoria), the enkephalins for mu and delta (less understood, perhaps associated in analgesia and reinforcement), and dynorphins for kappa receptors (implicated in spinal analgesia).

Opioid peptides appear to be endogenous ligands for the receptors activated by morphine and related compounds (Anderson \& Hoshino, 1997). Some of the behavioral effects of opiate administration include (a) insensitivity to pain, (b) affective lability, (c) stereotyped behaviors, and (d) reduced socialization (Kalat, 1978; Panksepp, 1979; Sandman, 1991, 1992). Since these effects are consistent with some of the symptoms of autism, researchers have theorized that an increase in opioid functioning could play a role in the disorder (e.g., Panksepp, 1979; Anderson, 1994). This hypothesis has been tested by assessing opioid levels (beta-endorphin, in particular) in the blood and CSF, as well as by the administration of opiate agonists.

\subsection{Blood and CSF studies}

Previous studies examining levels of endogenous opioids in the blood have yielded inconsistent results. These studies are summarized in Table 5. Nine studies were located, all of which examined levels of beta-endorphin (BE). Four groups of investigators reported elevated levels in subjects with autism, while four other groups reported decreased levels when compared to control groups. Three studies reported equivocal findings. It is notable that BE in the plasma is derived from the pituitary, and does not cross the blood-brain barrier. Therefore, it is not a clear indicator of central functioning; rather, elevated levels of BE in the blood appear to reflect acute stress (Tordjman et al., 1997; Anderson \& Hoshino, 1997). It is then possible that any elevated BE in blood could be a result of the stress of the blood draw itself, and therefore, not give a sense of baseline BE levels.

Studies of endogenous opioids in cerebrospinal fluid are less common (see Table 5). Three studies were located, one of which indicated elevated levels when compared to controls (Ross, Klykylo, \& Hitzemann, 1987), one which displayed decreased levels (Gillberg, Hagberg, Witt-Engerstom, \& Eriksson, 1990) and one which showed levels similar to controls (Nagamitsu, 1993). It is difficult to draw any conclusions from these studies, especially considering the small number of subjects employed and the use of control subjects that may not be representative [e.g., using normal adults as a control group for children with autism (Gillberg et al., 1990)].

At this point, the study of opioid activity in autism has produced little of clinical relevance beyond the symptomatic reduction of self-injury and hyperactivity in some subjects.

\subsection{Clinical/treatment implications}

A number of investigators have examined the effects of opiate antagonists (naloxone and naltrexone) in individuals with autism, under the assumption that opioid hyperfunction may be an important mediator of autistic behavior. Most of these studies used naltrexone, and the effects on core symptoms of autism were modest, at best (Sandman, 1988; Herman et al., 1986; Campbell et al., 1989; Leboyer et al., 1992; Campbell et al., 1993). However, some studies showed a reduction in self-injurious behavior. The inconsistent benefit (varying from patient to patient) of opiate antagonists for self-injurious behavior is worth considering even if there is no benefit for core 
autistic symptoms. Self injury resistant to behavioral treatment is such a severe problem when it occurs that any treatment that can assist in its management on a case-by-case basis must be regarded as an asset. One serendipitous finding in the studies that looked for an effect of naltrexone on autism was a fairly consistent effect in reducing symptoms of hyperactivity and impulsive behavior (Aman \& Langworthy, 2000). If confirmed and found to be safe, this could be an important use of naltrexone in this very vulnerable population. 


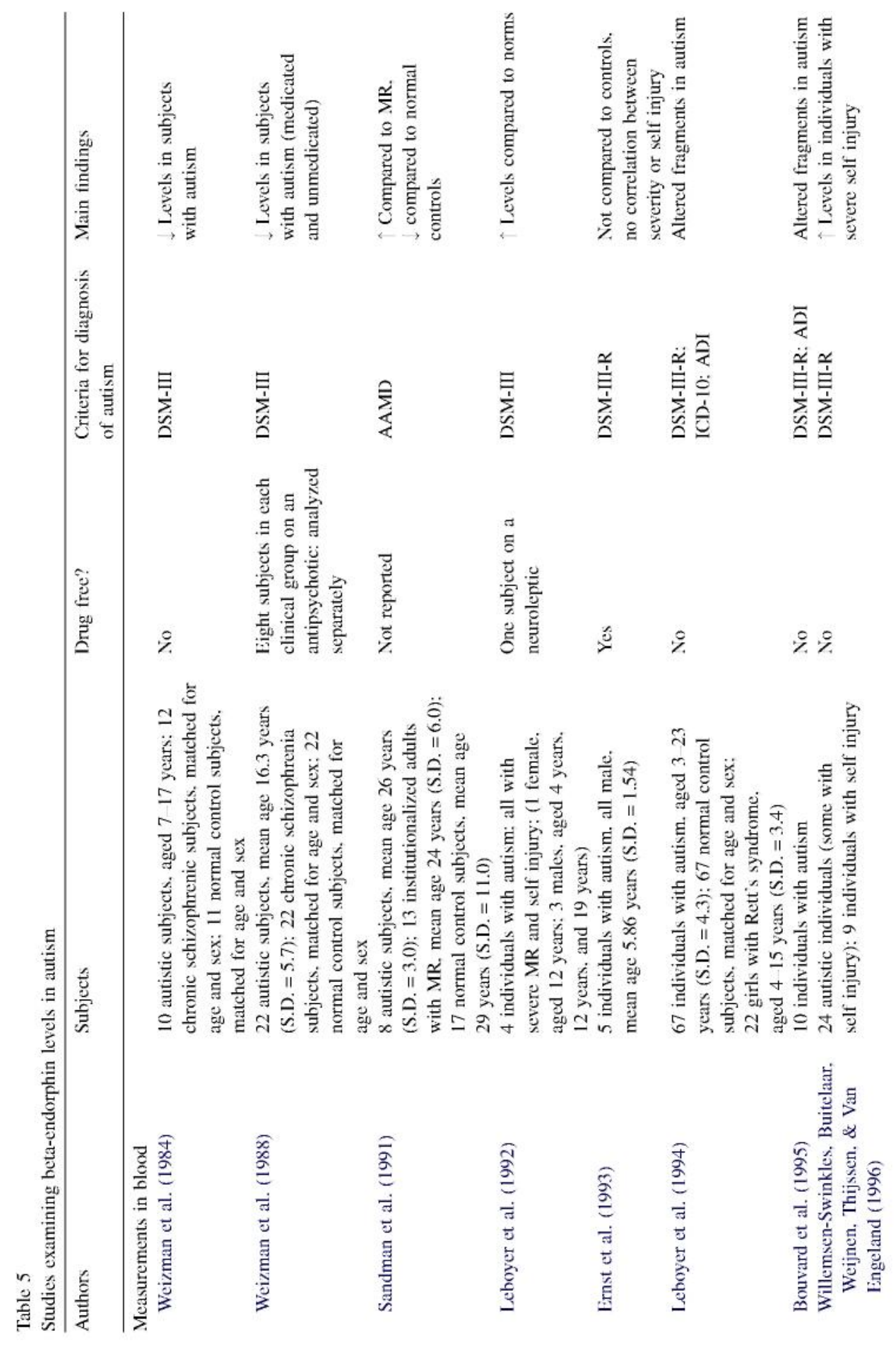




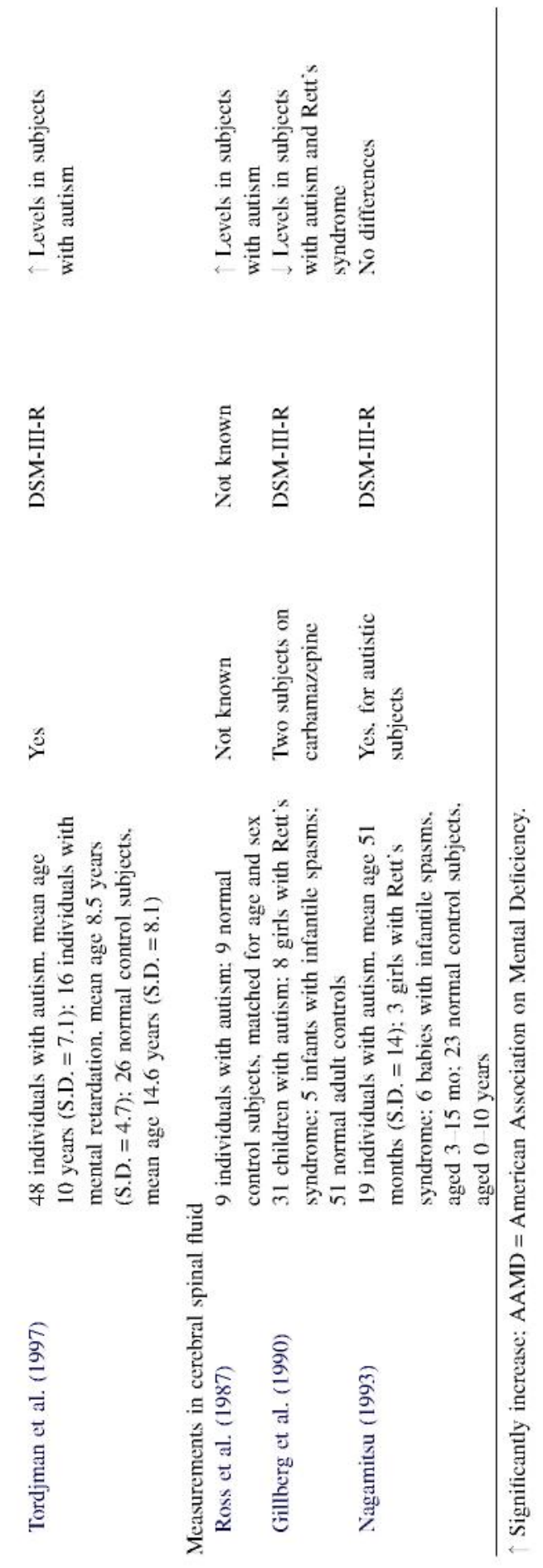




\section{Cortisol}

Cortisol is a glucocorticoid that is released by the adrenal cortex in response to stress. Its secretion is controlled by the hormone adrenocorticotropin (ACTH), which is released from the pituitary. ACTH release, in turn, is under the control of corticotropin-releasing factor (CRF) which is produced in the hypothalamus. Normally, cortisol limits its own release via a feedback loop, by suppressing the release of CRF and ACTH. Abnormalities in this feedback mechanism have been studied extensively in depression, using the dexamethasone suppression test (DST; Gwirtsman, Gerner, \& Sternbach, 1982).

Cortisol functioning in autism has been evaluated to assess the theory that some of the related behavioral disturbances could be due to a chronic heightened level of activation and hyperarousal, which might result in elevated levels of this stress hormone. Eleven studies (summarized in Table 6) have examined basal levels of cortisol, ACTH, or response to dexamethasone. Five studies using blood measurements of cortisol or ACTH found no differences between autistic and control subjects, which suggests that baseline levels of cortisol functioning are not greatly altered in autism. The largest study, involving 48 individuals with autism, did find significantly elevated levels of ACTH and normal levels of cortisol (Tordjman et al., 1997). It has been established that plasma ACTH is a good marker for acute stress. Cortisol, on the other hand, has a longer half-life and has a significantly longer latency to respond to stress, providing a better measure for basal stress levels (Tordjman et al., 1997). Therefore, rather than providing evidence for a chronic hyperarousal state, these results suggest that individuals with autism exhibit a heightened stress response to experimental procedures, such as the drawing of blood. These results are in agreement with observations of elevated blood NE and BE discussed previously.

It is interesting, however, that the two studies involving DST have shown that some individuals with autism do not display normal suppression of cortisol. This finding may provide further evidence for abnormalities in serotonergic or noradrenergic functioning, as workers have suggested that these neurotransmitters may have a regulatory effect on ACTH and CRF release (Butterweck, Winterhoff, \& Herkenham, 2001; Maccari et al., 1992; Stokes \& Sikes, 1987). Further research is needed to clarify these findings.

\subsection{Clinical/treatment implications}

Other areas of medicine make use of agents that mimic, suppress, or regulate the HPA axis. Unfortunately, such strategies carry considerable risk, so the benefits would have to be considerable to justify this as a therapeutic approach. We were unable to find therapeutic trials of medications that affect cortisol release in subjects with autism.

\section{Amino acid neurotransmitters: glutamate and GABA}

Glutamate and gamma-aminobutyric acid (GABA) are the two transmitter substances that are linked to widespread synaptic communication in the CNS. Glutamate is the principal excitatory transmitter substance in the brain and spinal cord, whereas GABA is responsible for most of the inhibitory communication in the brain (Carlson, 2001; Kandel 


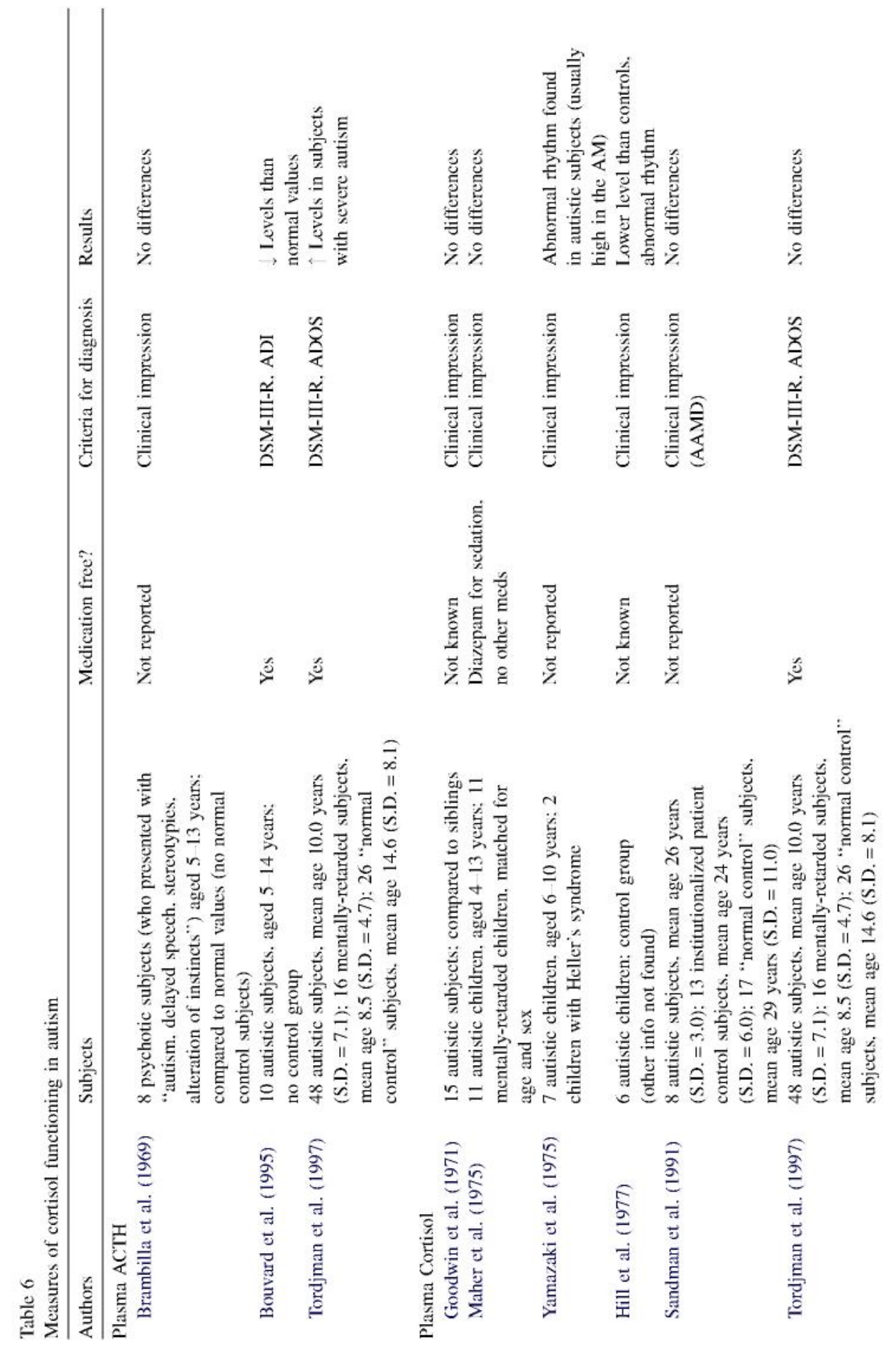




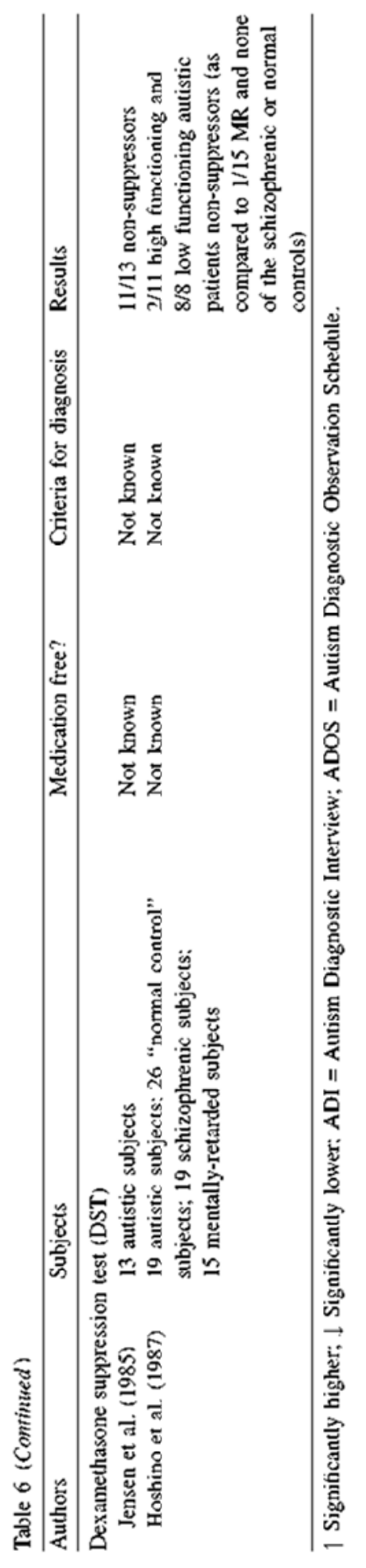


et al., 1995). Glycine is the principle inhibitory transmitter in the spinal cord and lower brain stem. These substances are widely produced in the central nervous system by the cells' metabolic processes, and their effects are very widespread; there are few, if any, areas in the brain that do not receive input from glutamate and GABA (Carlson, 2001). Research in these two neurotransmitters has been tightly-linked, as GABA is converted from glutamate by the enzyme glutamic acid decarboxylase (GAD). GAD is the rate-limiting step of the synthesis of GABA.

Despite their pervasiveness in brain activity and function, these amino acid neurotransmitters have received very little attention in the study of autism. However, researchers have begun to investigate whether or not either substance could play a role in autism's expression. This is, in some respects, a different approach from previous neurochemical investigations. Rather than trying to identify multiple abnormalities in relatively independent systems, the study of glutamate and GABA posits that autism may be the result of a single dysfunction that in turn has broad repercussions (Hussman, 2001).

Most theories regarding these amino acid neurotransmitters in autism suggest that the GABAergic system is suppressed, resulting in excessive stimulation of the glutamate system. This can be attributed to several findings. First, researchers have found abnormalities of cellular development in the limbic system and cerebellum postmortem (Bauman \& Kemper, 1994; Raymond, Bauman, \& Kemper, 1996). These areas are normally enriched with glutamate receptors. Researchers have theorized that overactivity of glutamate could result in "excitotoxicity" which could cause aberrant neuronal development (Bittigau \& Ikonomidou, 1997). In addition, glutamate activity peaks during the second year of life (Kornhuber, Mack-Burhardt, Konradi, Fritze, \& Riderer, 1989), which is a time when symptoms of autism often emerge. If this system is hyperfunctional, it is possible that neuronal growth and connectivity are damaged during critical periods of development. Excessive glutamatergic stimulation is also associated with seizures, which are common among individuals with autism (Hussman, 2001).

Recently, a group of researchers examined brain levels of GAD, the rate-limiting step in the synthesis of GABA, in five autistic and eight control subjects postmortem (Fatemi et al., 2002). They found that this enzyme was reduced by $48-61 \%$ in parietal and cerebellar areas of brains of individuals with autism when compared to controls. These differences were statistically significant, and provided some initial evidence for abnormalities in glutamate/GABA.

At this point, it is unclear as to whether or not an imbalance in the glutamate and GABA neurotransmitters contributes to the etiology of autism. However, postmortem research in this area is intriguing, and further research is needed.

\subsection{Clinical/treatment implications}

Much is already known about both glutamate and GABA metabolism and neurotransmission in general that might be applied empirically case-by-case in autism. The classic GABAergic agents available, such as clonazepam and lorazepam, seem of relatively low risk other than addiction or sudden withdrawal. Another intriguing possibility, one that would require long-term research to establish benefit-risk ratio, would be preventive treatment with GABA agents when autism first manifests in toddlerhood to neutralize excess glutamate excitotoxicity and to prevent progression of the disorder. However, the existing trials are not cause for optimism. Two studies examining pharmacologic treatments that affect the glutaminergic system were located. One assessed the effects of lamotrigine, which is thought to modulate glutamate's activity but which also weakly inhibits the serotonin 5HT3 receptor (Belsito, Law, Kirk, Landa, \& Zimmerman, 2001). In a double-blind, placebo-controlled study, either lamotrigine or placebo was 
administered to twenty-eight children with autism, aged between 3 and 11 years, chosen for the presence of autism but no additional behavioral symptoms. Very little improvement in autism symptoms was noted with treatment with active drug. King et al. (2001) reported findings from a double-blind, placebo-controlled study of amantadine (an antagonist at the $N$-methyl-D-aspartate subtype of glutamate receptor but also with anticholinergic effects) in 39 subjects with autistic disorder. While significant improvements were noted on the clinician-rated scores for Hyperactivity and Inappropriate Speech subscales of the Aberrant Behavior Checklist (Aman, Singh, Stewart, \& Field, 1985) during treatment with amantadine, no differences from placebo were noted for parent measures (Aberrant Behavior Checklist) and in clinician's ratings of global improvement.

Hollander, Dolgoff-Kasper, Cartwright, Rawitt, and Novotny (2001) openly treated 14 patients (mostly children) with autism spectrum disorders with divalproex sodium (DVPX). DVPX inhibits catabolic enzymes of GABA, but it also blocks voltage-dependent sodium channels. The patients were described as having affective instability (e.g., were impulsive and aggressive). Retrospective analysis suggested that 10 patients (72\%) showed improved behavior with DVPX. Marrosu, Marrosu, Rachel, and Biggio (1987) described a series of seven children with autism who received intramuscular injections of diazepam and saline. Six of the seven children showed hyperactivity and all exhibited aggression when medicated with diazepam. Such an adverse response should not be surprising. It has long been known that children often show "paradoxical" excitability when treated with anxiolytic/sedatives (Werry \& Aman, 1999) and children with autism appear to be no exception.

\section{Discussion}

At first glance, the bulk of neurochemical research in autism has been inconclusive, contradictory, and somewhat disappointing. Most of these studies employed few subjects and included comparison groups that were not appropriate, making it difficult to draw clear-cut conclusions. However, there appear to be some areas that may prove fruitful for future researchers. Clearly, serotonin remains the most promising area for future neurochemical research. With the development of sophisticated imaging and genetic techniques, researchers are beginning to delineate the potential abnormalities in central serotonergic functioning, such as focal regions of abnormal 5-HT synthesis and possible genetic differences in 5-HT transport. These preliminary results are intriguing and are in need of further study and replication.

Recent work in neuropeptide functioning has suggested that oxytocin may also play a role in the pathogenesis of the disorder. This area of research is in its infancy, and further study is needed; particularly, it would be useful to get more direct central assessments of oxytocin via measurement of CSF. In addition, studies using positron-emission tomography to investigate central OT receptor distribution may also help elucidate the role of oxytocin in autism (Modahl et al., 1998).

The place of neurotransmitters in early brain development (e.g., serotonin, acetylcholine, and glutamate) may prove to be a particularly important area of study. If certain systems are disrupted early in the development of the brain, it is possible that early pharmacological intervention could possibly help to treat and maybe even prevent some of the devastating features of autistic disorder. Theoretically, work in genetics may be able to identify these neurochemical abnormalities at birth, which may help to direct infants who are at risk for autism into the appropriate medical treatment. This would represent a completely new approach to the pharmacological management of autism.

Review of the other neurochemical systems in autism was not as compelling. The evidence 
for DA's role in autism was not convincing; however, there are discrepancies among the studies of central DA turnover, so further replication may be warranted. The studies of noradrenergic functioning have not provided any evidence for a clear role in autism's pathogenesis, and it is unlikely that further investigation would prove otherwise. Studies of opioid functioning in autism have not produced much of clinical relevance thus far. Studies of baseline levels of cortisol have not shown any consistent abnormalities, though a high rate of non-suppression after dexamethasone warrants further pursuit.

Upon review of this body of work, several methodological issues need to be addressed by future researchers. First, it is critical that future studies carefully assess and categorize research subjects by strict diagnostic and subject criteria for autism. Perusal of Tables 1-6 reveals that everything from "clinical impression" through to rigorous structured interview has been used in the past, but entry has relied on informal methods of classification in the past. Future research needs to go beyond the sole reliance on diagnostic methods such as the DSM-IV and the ADI-R in classifying subjects. Though these tools may be able to diagnose an individual with autistic disorder, there are inconsistent symptom profiles across individuals who meet these criteria. For example, individuals may be severely or mildly impaired, and may exhibit comorbid behavioral disturbances such as hyperactivity, aggression, or anxiety - such subject factors may likely reflect neurochemical function. Furthermore, recent research has also established that factors such as pubertal status and race can have significant effects on biochemical measurements. These characteristics must also be accounted for in control groups. Researchers need to control for these subject variables, and in doing so, they will be able to delineate what is unique to the pathophysiology of autism, and possibly reveal subcategories within the disorder that may guide future pharmacotherapy.

Second, much of the neurochemical research in the past 35 years or so has focused on peripheral measures of neurochemical systems; this has limited what conclusions could be made about central functioning. However, recent advances in the basic neurosciences (such as PET, genetic techniques, and more sensitive assay methods) have opened the way to more relevant and informative assessments of central functioning. Thus, in time, the greatest challenge to meaningful neurochemical investigation in autism may well be the issues of clinical assessment discussed above (rather than limitations in neurobiological assessment).

Third, looking for abnormalities in only one neurochemical system may be akin to searching for the "Holy Grail". For example, it is not clear why the atypical antipsychotics are often helpful in managing problem behaviors in autism. In this case, it could be that there is a dynamic balance between serotonergic and dopaminergic systems, and that this varies between patients, as well as between drugs. For example, serotonin is also known to have a regulatory action on dopamine levels. This idea of dynamic interaction might also be applied to other neurotransmitters, neuropeptides, and so forth. Thus, it may be more fruitful to look for a pattern of imbalance between candidate neurotransmitters than for simple elevations and deficiencies.

Fourth, it is clear that the various subspecialties within the biological bases of behavior must continue (and increase) their collaborative efforts. The disciplines of neurochemistry, neuroanatomy, psychopharmacology, and genetics should work in concert to help uncover the biological bases of this disorder. It is becoming clear that autism may involve a cascade of complex gene-environmental interactions, and the study of neurochemistry in isolation may not be sufficient. This includes approaching the study of autism from a developmental perspective, investigating how early neuronal growth and differentiation could be aberrant or interrupted in individuals with the disorder. Recent advances in pharmacogenomics may prove to be a fruitful area of research, as may 
the continued postmortem studies of receptor distribution and neurochemistry. Bringing together experts of these respective areas to work in collaboration with one another is an exciting development that will hopefully lead to better treatments, if not a cure or prevention for this debilitating disorder.

\section{References}

Aman, M. G., Arnold, L. E., \& Armstrong, S. C. (1999). Review of serotonergic agents and perseverative behavior in patients with developmental disabilities. Mental Retardation and Developmental Disabilities Research Reviews, 5, 279-289.

Aman, M. G., \& Kern, R. A. (1989). Review of fenfluramine in the treatment of the developmental disabilities. Journal of the American Academy of Child and Adolescent Psychiatry, 28, 549-565.

Aman, M. G., Lam, K. S. L., \& Collier-Crespin, A. (2003). Prevalence and patterns of use of psychoactive medicines among individuals with autism in the Autism Society of Ohio. Journal of Autism and Developmental Disorders, 33, 527-534.

Aman, M. G., \& Langworthy, K. S. (2000). Pharmacotherapy for hyperactivity in children with autism and other pervasive developmental disorders. Journal of Autism and Developmental Disorders, 30, 451-459.

Aman, M. G., \& Singh, N. N. (1994). Aberrant behavior checklist-community. Supplementary manual. East Aurora, NY: Slosson Educational Publications.

Aman, M. G., Singh, N. N., Stewart, A. W., \& Field, C. J. (1985). The aberrant behavior checklist: a behavior rating scale for the assessment of treatment effects. American Journal of Mental Deficiency, 89, 485-491.

Amaral, D. G., \& Sinnamon, H. M. (1977). The locus coeruleus: neurobiology of a central noradrenergic nucleus. Progress in Neurobiology, 9, 147-196.

American Psychiatric Association. (1994). Diagnostic and statistical manual of mental disorders (4th ed.). Washington, DC: American Psychiatric Association.

Anderson, G. M. (1994). Studies on the neurochemistry in autism. In M. L. Bauman, \& T. L. Kemper (Eds.), The Neurobiology of Autism (pp. 227-242). Baltimore: Johns Hopkins University Press.

Anderson, G. M., Freedman, C. X., Cohen, D. J., Volkmar, F. R., Hoder, E. L., McPhedran, P., et al. (1987). Whole blood serotonin in autistic and normal subjects. Journal of Child Psychology and Psychiatry, 28, 885-900.

Anderson, G. M., \& Hoshino, Y. (1997). Neurochemical studies of autism. In D. J. Cohen, \& F. R. Volkmar (Eds.), Handbook of autism and pervasive developmental disorders (2nd ed., pp. 325-343). New York: Wiley.

Angold, A., Costello, E. J., \& Erkanli, A. (1999). Comorbidity. Journal of Child Psychology and Psychiatry and Allied Disciplines, 40, 57-87.

Bailey, A., LeCouteur, A., Gottesman, I., Bolton, P., Simonoff, E., Yuzda, E., et al. (1995). Autism as a strongly genetic disorder: evidence from a British twin study. Psychological Medicine, 25, 63-78.

Barberis, C., \& Tribollet, E. (1996). Vasopressin and oxytocin receptors in the central nervous system. Critical Reviews in Neurobiology, 10, 119-154.

Barthelemy, C., Bruneau, N., Cottet-Eymard, J. M., Domenech-Jouve, J., Garreau, B., Lelord, G., et al. (1988). Urinary free and conjugated catecholamine and metabolites in autistic children. Journal of Autism and Developmental Disorders, 18, 585-591.

Bauman, M. L., \& Kemper, T. L. (1994). Neuroanatomic observations of the brain in autism. In M. L. Bauman, \& T. L. Kemper (Eds.), The neurobiology of autism (pp. 119-145). Baltimore: The Johns Hopkins University Press.

Belendiuk, K., Belendiuk, G. W., \& Freedman, D. X. (1980). Blood monoamine levels in Huntington's disease. Archives of General Psychiatry, 37, 325-332.

Belsito, K. M., Law, P. A., Kirk, K. S., Landa, R. J., \& Zimmerman, A. J. (2001). Lamotrigine therapy for autistic disorder: A randomized, double-blind, placebo-controlled trial. Journal of Autism and Developmental Disorders, 31, 175-181.

Bittigau, P., \& Ikonomidou, C. (1997). Glutamate in neurologic diseases. Journal of Child Neurology, 12, 471-485.

Bolton, P., Macdonald, H., Pickles, A., Rios, P., Goode, S., Crowson, M., et al. (1994). A case-controlled family history study of autism. Journal of Child and Adolescent Psychiatry, 35, 877-900.

Bouvard, M. P., Leboyer, M., Launay, J., Recasens, C., Plumet, M., Waller-Perotte, D., et al. (1995). Low-dose naltrexone effects on plasma chemistries and clinical symptoms in autism: A double-blind, placebo-controlled study. Psychiatry Research, 58, 191-201.

Brambilla, F., Viani, F., \& Rossotii, V. (1969). Endocrine aspects of child psychoses. Diseases of the Nervous System, 30, 627-632.

Bristol, M. M., Cohen, D. J., Costello, E. J., Denckla, M., Eckberg, T. J., \& Kallen, R. (1996). State of the science in 
autism: report to the National Institutes of Health. Journal of Autism and Developmental Disorders, 26, 121-154.

Butterweck, V., Winterhoff, H., \& Herkenham, M. (2001). St. John's wort, hypericin, and imipramine: a comparative analysis of mRNA levels in brain areas involved in HPA axis control following short-term and long-term administration in normal and stressed rats. Molecular Psychiatry, 6, 547-564.

Calne, D., Chase, T. N., \& Barbeau, A. (1975). Dopaminergic mechanisms. Advances in Neurology, Vol. 9, New York: Raven Press.

Campbell, M., Anderson, L. T., Small, A. M., Adams, P., Gonzalez, N. M., \& Ernst, M. (1993). Naltrexone in autistic children: Behavioral symptoms and attentional learning. Journal of the American Academy of Child and Adolescent Psychiatry, 32, 1263-1271.

Campbell, M., Anderson, L. T., \& Small, A. M. (1990). Pharmacotherapy in autism. Brain Dysfunction, 3, $299-307$.

Campbell, M., Friedman, E., Green, W. H., Collins, P. J., Small, A. M., \& Breuer, H. (1975). Blood serotonin in schizophrenic children: A preliminary study. International Pharmacopsychiatry, 10, 213-221.

Campbell, M., Overall, J. E., Small, A. M., Sokol, M. S., Spencer, E. K., \& Andams, et al. (1989). Naltrexone in autistic children: an acute open dose range tolerance trial. Journal of the American Academy of Child and Adolescent Psychiatry, 28, 200-206.

Campbell, M., Petti, T. A., Greene, W. H., Cohen, I. L., Genieser, H. B., \& David, R. (1980). Some physical parameters of young autistic children. Journal of the American Academy of Child and Adolescent Psychiatry, 19, 193-212.

Carlson, N. R. (2001). Physiology of behavior (7th ed., pp. 96-129). Boston: Allyn and Bacon.

Chakrabarti, S., \& Fombonne, E. (2001). Pervasive developmental disorders in preschool children. Journal of the American Medical Association, 285, 3093-3099.

Chamberlain, R. S., \& Herman, B. H. (1990). A novel biochemical model linking dysfunctions in brain melatonin, proopiomelanocortin peptides, and serotonin in autism. Biological Psychiatry, 28, 773-793.

Chez, M. G., Aimonovitch, M., Buchanan, T., Mrazek, S., \& Tremb, R. J. (2004). Treating autistic spectrum disorders in children: Utility of the cholinesterase inhibitor rivastigmine tartrate. Journal of Child Neurology, 19, 165-169.

Chez, M. G., Tremb, R. J., Nowinski, C. V., \& Field-Chez, M. (2001). Double-blinded placebo-controlled Aricept study in children with autism spectrum disorder. In Proceedings of the Abstract presented at: 30th Annual Meeting of the Child Neurology Society, 17-20 October, Victoria, BC, Canada.

Chugani, D. C., Muzik, O., Rothermel, R., et al. (1997). Altered serotonin synthesis in the dentatothalamocortical pathway in autistic boys. Annals of Neurology, 14, 666-669.

Chugani, D. C., Muzik, O., Behen, M., Rothermel, R., Janisse, J. J., Lee, J., et al. (1999). Developmental changes in brain serotonin synthesis capacity in autistic and nonautistic children. Annals of Neurology, 45, 287-295.

Cohen, D. J., Shaywitz, B. A., Johnson, W. T., \& Bowers, M. B., Jr. (1974). Biogenic amines in autistic and atypical children: Cerebrospinal fluid measures of homovanillic acid and 5-hydroxyindoleacetic acid. Archives of General Psychiatry, 31, 845-853.

Cohen, D. J., Caparulo, B. K., Shaywitz, B. A., \& Bowers, M. B., Jr. (1977). Dopamine and serotonin metabolism in neuropsychiatrically disturbed children: CSF homovanillic acid and 5-hydroxyindoleacetic acid. Archives of General Psychiatry, 34, 545-550.

Cook, E. H. (1990). Autism: Review of neurochemical investigation. Synapse, 6, $292-308$.

Cook, E. H., Jr., Courchesne, R., Lord, C., Cox, N. J., Yan, S., Lincoln, N., et al. (1997). Evidence of linkage between the serotonin transporter and autistic disorder. Molecular Psychiatry, 2, 247-250.

Cook, E. H., Leventhal, B. L., \& Freedman, D. X. (1988). Free serotonin in plasma: Autistic children and their first-degree relatives. Biological Psychiatry, 24, 488-491.

Cook, E. H., Leventhal, B. L., Heller, W., Metz, J., Wainwright, M., \& Freedman, D. X. (1990). Autistic children and their first-degree relatives: Relationships between serotonin and norepinephrine levels and intelligence. Journal of Neuropsychiatry and Clinical Neurosciences, 2, 268-274.

Cook, E. H., Rowlett, R., Jaselskis, C., \& Leventhal, B. L. (1992). Fluvoxetine treatment of children and adults with autistic disorder and mental retardation. Journal of the American Academy of Child and Adolescent Psychiatry, 31, 739-745.

Costa, E., \& Gessa, G. L. (1977). Nonstriatal dopaminergic neurons. Advances in Biochemical Psychopharmacology, Vol. 6, New York: Raven Press.

Croonenberghs, J., Delmerie, L., Verkerk, R., Lin, A., Meskal, A., Neels, H., et al. (2000). Peripheral markers of serotonergic and noradrenergic function in post-pubertal, caucasian males with autistic disorder.

Neuropsychopharmacology, 22, 275-283.

Cuccaro, M. L., Wright, H. H., Abramson, R. K., Marsteller, F. A., \& Valentine, J. (1993). Whole-blood serotonin and cognitive functioning in autistic individuals and their first-degree relatives. Journal of Neuropsychiatry and Clinical 
Neurosciences, 5, 94-101.

Davis, E., Fennoy, I., Laraque, D., Kanem, N., Brown, G., \& Mitchell, J. (1992). Autism and developmental abnormalities in children with perinatal cocaine exposure. Journal of the National Medical Association, 84, 315319.

Elchiasak, M. A., Polinsky, R. J., Ebert, M. H., Powers, J., \& Kopin, I. J. (1978). Contribution of plasma homovanillic acid (HVA) to urine and CSF HVA in the monkey and its pharmacokinetic dispostion. Life Sciences, 23, 23392348.

Ernst, M., Devi, L., Silva, R. R., Gonzalez, N. M., Small, A. M., Malone, R. P., et al. (1993). Plasma beta-endorphin levels, naltrexone, and haloperidol in autistic children. Psychopharmacology Bulletin, 29, 221-227.

Ernst, M., Malone, R. P., Rowan, A. B., George, R., Gonzalez, N. M., \& Silva, R. R. (1999). Antipsychotics (Neuroleptics). In J. S. Werry, \& M. G. Aman (Eds.), Practitioner's guide to psychoactive drugs for children and adolescents (pp. 297-327). New York: Plenum.

Fatemi, S. H., Halt, A. R., Stary, J. M., Kanodia, R., Schulz, S. C., \& Realmuto, G. R. (2002). Glutamic acid decarboxylase $65 \& 67 \mathrm{kDa}$ proteins are reduced in autistic parietal \& cerebellar cortices. Biological Psychiatry, 52, 805-810.

Fraser, W. I., Ruedrich, S., Kerr, M., \& Levitas, A. (1998). Beta-adrenergic blockers. In S. Reiss, \& M. G. Aman (Eds.), The international consensus handbook (pp. 271-289). Columbus, OH: The Ohio State University Nisonger Center.

Freedman, D. X., Belendiuk, K., Belendiuk, G. W., \& Crayton, J. W. (1981). Blood tryptophan metabolism in chronic schizophrenics. Archives of General Psychiatry, 38, 655-659.

Gillberg, C. (1993). Not less likely than before that mean CSF HVA may be high in autism. Biological Psychiatry, 34, $746-747$.

Gillberg, C., \& Coleman, M. (1992). The biology of autistic syndromes (2nd ed.). London: MacKeith Press.

Gillberg, C., Hagberg, B., Witt-Engerstom, I., \& Eriksson, I. (1990). CSF beta-endorphin in childhood neuropsychiatric disorders. Brain and Development, 12, 88-92.

Gillberg, C., Svennerholm, L., \& Hamilton-Helberg, C. (1983). Childhood psychosis and monoamine metabolites in spinal fluid. Journal of Autism and Developmental Disorders, 13, 383-396.

Gillberg, C., \& Svennerholm, L. (1987). CSF monoamines in autistic syndromes and other pervasive developmental disorders of early childhood. British Journal of Psychiatry, 151, 89-94.

Goodwin, M. S., Cowen, M. A., \& Goodwin, T. C. (1971). Malabsorption and cerebral dysfunction: a multivariate and comparative study of autistic children. Journal of Autism and Childhood Schizophrenia, 1, 148-162.

Gordon, C., State, R., Nelson, J., Hamburger, S., \& Rapoport, J. (1993). A double-blind comparison of clomipramine, desipramine, and placebo in the treatment of autistic disorder. Archives of General Psychiatry, 50, 441-447.

Gwirtsman, H., Gerner, R. H., \& Sternbach, H. (1982). The overnight dexamethasone suppression test: Clinical and theoretical review. Journal of Clinical Psychiatry, 43, 321-327.

Hanley, H. G., Stahl, S. M., \& Freedman, D. X. (1977). Hyperserotonemia and amine metabolites in autistic and retarded children. Archives of General Psychiatry, 34, 521-531.

Hardan, A. Y., \& Handen, B. L. (2002). A retrospective open trial of adjunctive donepezil in children and adolescents with autistic disorder. Journal of Child and Adolescent Psychopharmacology, 12, 237-241.

Herman, B. H., Hammock, M. K., Arthur-Smith, A., Egan, J., Chatoor, I., Zelnik, N., et al. (1986). Effects of naltrexone in autism: correlation with plasma opioid concentrations. In Proceedings of the American Academy of Child and Adolescent Psychiatry (pp. 11-12).

Hill, S. D., Wagner, E. A., Shedlarski, J. G., \& Sears, S. P. (1977). Diurnal cortisol and temperature variation of normal and autistic children. Developmental Psychobiology, 10, 579-583.

Hollander, E., Dolgoff-Kaspar, R., Cartwright, C., Rawitt, R., \& Novotny, S. (2001). An open trial of divalproex sodium in autistic spectrum disorders. Journal of Clinical Psychiatry, 62, 530-534.

Hollander, E., Novotny, S., Hanratty, M., Yaffe, R., DeCaria, C. M., Aronowitz, B. R., et al. (2003). Oxytocin infusion reduces repetitive behaviors in adults with autistic and Asperger's disorders. Neuropsychopharmacology, 28, 193198.

Hoshino, Y., Yokoyama, F., Hashimoto, S., Murata, S., Kaneko, M., \& Kumashiro, H. (1987). The diurnal variation and response to dexamethasone suppression test of saliva cortisol levels of autistic children. Japanese Journal of Psychiatry and Neurology, 41, 227-235.

Hussman, J. P. (2001). Suppressed GABAergic inhibition as a common factor in suspected etiologies of autism. Journal of Autism and Developmental Disorders, 31, 247-248.

Insel, T. R. (1992). Oxytocin: a neuropeptide for affiliation B evidence form behavioral, receptor autoradiographic, and comparative studies. Psychoneuroendocrinology, 17, 3-33.

Insel, T. R., \& Hulihan, T. J. (1995). A gender specific mechanism for pair bonding: oxytocin and partner preference 
formation in monogamous voles. Behavioral Neuroscience, 109, 782-789.

Insel, T. R., O’Brien, D. J., \& Leckman, J. F. (1999). Oxytocin, vasopressin, and autism: is there a connection? Biological Psychiatry, 45, 145-157.

Jensen, J. B., Realmuto, G. M., \& Garfinkel, B. D. (1985). The dexamethasone suppression test in infantile autism. Journal of the American Academy of Child and Adolescent Psychiatry, 24, 263-265.

Jorde, L. B., Mason-Brothers, A., Waldmann, R., Ritvo, E. R., et al. (1990). The UCLA-University of Utah epidemiologic survey of autism: Genealogical analysis of familial aggregation. American Journal of Medical Genetics, 36, 85-88.

Kalat, J. W. (1978). Letter to the editor: Speculations on similarities between autism and opiate addiction. Journal of Autism and Childhood Schizophrenia, 8, 477-479.

Kandel, E. R., Schwartz, J. H., \& Jessell, T. M. (1995). Essentials of neural science and behavior. Norwalk, Connecticut: Appleton and Lange. pp. 296-297.

King, B. H., Wright, D. M., Handen, B. L., Sikich, L., Zimmerman, A. W., McMahon, W., et al. (2001). Double-blind, placebo-controlled study of amantadine hydrochloride in the treatment of children with autistic disorder. Journal of the American Academy of Child and Adolescent Psychiatry, 40, 658-665.

Klauck, S. M., Poutska, F., Benner, A., Lesch, K., \& Poutska, A. (1997). Serotonin transporter (5-HTT) gene variants associated with autism? Human Molecular Genetics, 6, 2233-2238.

Kornhuber, J., Mack-Burhardt, F., Konradi, C., Fritze, J., \& Riderer, P. (1989). Effect of antemortem and postmortem factors on [3H]MK-801 binding in the human brain: Transient elevation during early childhood. Life Science, 45, $745-749$.

Kramer, K., Azmita, E. C., \& Whitaker-Azmita, P. M. (1994). In vitro release of [3H]5-hydroxytryptamine from fetal and maternal brain by drugs of abuse. Brain Research Developmental Brain Research, 78, 142-146.

Lake, C. R., Ziegler, M. G., \& Murphy, D. L. (1977). Increased norepinephrine levels and decreased dopamine-beta-hydroxylase activity in primary autism. Archives in General Psychiatry, 34, 553-556.

Langworthy-Lam, K. S., Aman, M. G., \& Van Bourgondien, M. E. (2002). Prevalence and patterns of use of psychoactive medicines in individuals with autism in the Autism Society of North Carolina. Journal of Child and Adolescent Psychopharmacology, 12, 311-322.

Launay, J. M., Burztein, C., Ferrari, P., et al. (1987). Catecholamine metabolism in infantile autism: a controlled study of 22 autistic children. Journal of Autism and Developmental Disorders, 17, 333-347.

Leboyer, M., Bouvard, M. P., \& Launay, J. M. (1992). A double-blind study of naltrexone in infantile autism. Journal of Autism and Developmental Disorders, 17, 333-347.

Leboyer, M., Bouvard, M. P., Racasens, C., Philippe, A., Guilloud-Bastaille, M. F., Bondoux, D., et al. (1994). Difference between plasma N- and C-terminally directed beta-endorphin immunoreactivity in infantile autism. American Journal of Psychiatry, 151, 1797-1810.

Leckman, J. F., Cohen, D. J., Shaywitz, B. A., Caparulo, B. K., Heninger, G. R., \& Bowers, M. B., Jr. (1980). CSF monoamine metabolites in child and adult psychiatric patients'. A developmental perspective. Archives of General Psychiatry, 37, 677-681.

Lee, M., Martin-Ruiz, C., Graham, A., Court, J., Jaros, E., Perry, R., et al. (2002). Nicotinic receptor abnormalities in the cerebellar cortex in autism. Brain, 125, 1483-1495.

Lesch, K. P., Wolozin, B. L., Murphy, D. L., \& Riederer, P. (1993). Primary structure of the human platelet serotonin (5-HT) uptake site: Identity with the brain 5-HT transporter. Journal of Neurochemistry, 60, 2319-2322.

Leventhal, B. L., Cook, E. H., Jr., Morford, M., Raviatz, A., \& Freedman, D. X. (1990). Relationships of whole blood serotonin and plasma norepinephrine within families. Journal of Autism and Developmental Disorders, 22, 309-319.

Lord, C. (1995). Follow-up of two-year-olds referred for possible autism. Journal of Child Psychology and Psychiatry, 36, 1365-1382.

Lord, C., Rutter, M., \& Le Couteur, A. (1994). Autism Diagnostic Interview—Revised: a revised version of a diagnostic interview for caregivers of individuals with possible pervasive developmental disorders. Journal of Autism and Developmental Disorders, 24, 659-685.

Maas, J. W., Hattox, S. E., Greene, N. M., \& Landis, B. H. (1980). Estimates of dopamine and serotonin synthesis by the awake human brain. Journal of Neurochemistry, 34, 1547-1549.

Maccari, S., Piazza, P. V., Rouge-Pont, F., Angelucci, L., Simon, H., \& le Moal, M. (1992). Noradrenergic regulation of type-I and type-II corticosteroid receptors in amygdala and hypothalamus. Brain Research, 587, 313-318.

Maestrini, E., Lai, C., Marlow, A., Matthews, N., Wallace, S., Bailey, A., et al. (1999). Serotonin transporter (5-HTTT) and gamma-aminobutyric acid receptor subunit beta-three (GABRB3) gene polymorphisms are not associated with autism in the IMGSA families. American Journal of Medical Genetics, 88, 492-496.

Maher, K. R., Harper, J. F., Macleay, A., \& King, M. G. (1975). Peculiarities in the endocrine response to insulin stress in 
early infantile autism. Journal of Nervous and Mental Disorders, 161, 180-184.

Marrosu, F., Marrosu, G., Rachel, M. G., \& Biggio, G. (1987). Paradoxical reactions elicited by diazepam in children with classic autism. Functional Neurology, 3, 355-361.

Marsden, C. A. (1981). Effect of L-tryptophan on mouse brain 5-hydroxytryptamine: comparison of values obtained using a fluorimetric assay and a liquid chromatographic assay with electrochemical detection. Journal of Neurochemistry, 36, 1621-1626.

Martin-Ruiz, C. M., Lee, M., Perry, R. H., Baumann, M., Court, J. A., \& Perry, E. K. (2004). Molecular analysis of nicotinic receptor expression in autism. Molecular Brain Research, 123, 81-90.

Martineau, J., Barthelemy, C., Jouve, J., Muh, J. P., \& Lelord, G. (1992). Monoamines (serotonin and catecholamines) and their derivatives in infantile autism: age-related changes and drug effects. Developmental Medicine and Child Neurology, 34, 593-603.

McBride, P. A., Anderson, G. M., Hertzig, M. E., Snow, M. E., Thompson, S. M., Khait, V. D., et al. (1998). Effects of diagnosis, race, and puberty of platelet serotonin levels in autism and mental retardation. Journal of the American Academy of Child and Adolescent Psychiatry, 37, 767-776.

McDougle, C. J., Naylor, S. T., Cohen, D. J., Aghajanian, G. K., Heninger, G. R., \& Price, L. H. (1996a). Effects of tryptophan depletion in drug-free adults with autistic disorder. Archives of General Psychiatry, 53, 993-1000.

McDougle, C. J., Naylor, S. T., Cohen, D. J., Volkmar, F., Heniger, G. R., \& Price, L. (1996b). A double-blind, placebo-controlled study of fluvoxamine in adults with autistic disorder. Archives of General Psychiatry, 53, 10011008.

McDougle, C. J., \& Posey, D. J. (2003). Autistic and other pervasive developmental disorders. In A. Martin, L. Scahill, D. S. Charney, \& J. F. Leckman (Eds.), Pediatric psychopharmacology (pp. 563-579). New York, NY: Oxford University Press.

McDougle, C. J., Scahill, L., Aman, M. G., McCracken, J. T., Tierney, E., Davies, M., et al. (in press). Risperidone for the core symptom domains of autism: Results from the RUPP Autism Network study. American Journal of Psychiatry.

Minderaa, R. B., Anderson, G. M., Volkmar, F. R., Harcherick, D., Akkerhuis, C. W., \& Cohen, D. J. (1989). Neurochemical study of dopamine functioning in autistic and normal subjects. Journal of the American Academy of Child and Adolescent Psychiatry, 28, 200-206.

Minderaa, R. B., Anderson, G. M., Volkmar, F. R., Akkerhuis, G. W., \& Cohen, D. J. (1994). Noradrenergic and adrenergic functioning in autism. Biological Psychiatry, 36, 237-241.

Modahl, C., Green, L. A., Fein, D., Morris, M., Waterhouse, L., Feinstein, C., et al. (1998). Plasma oxytosin levels in autistic children. Biological Psychiatry, 43, 270-277.

Moore, R. Y., \& Bloom, F. E. (1979). The locus coeruleus: Neurobiology of a central noradrenergic nucleus. Annual Review of Neuroscience, 2, 113-168.

Nagamitsu, S. (1993). CSF beta-endorphin levels in pediatric neurologic disorders. Kurume Medical Journal, 40, $233-$ 241.

Nanson, J. L. (1992). Autism in fetal alcohol syndrome: A report of six cases. Alcohol Clinical Experimental Research, 16, 558-565.

Narayan, M., Srinath, S., Anderson, G. M., \& Meundi, D. B. (1992). Cerebrospinal fluid levels of homovanillic acid and 5-hydroxyindoleacetic acid in autism. Biological Psychiatry, 33, 630-635.

Niederhofer, H., Staffen, W., \& Mair, A. (2002). Galantamine may be effective in treating autistic disorder. British Medical Journal, 325, 1422.

Panksepp, J. (1979). A neurochemical theory of autism. Trends in Neuroscience, 2, 174-177.

Pare, C. M. B., Sandler, M., \& Stacey, R. S. (1960). 5-Hydroxyindoles in mental deficiency. Journal of Neurology, Neurosurgery, and Psychiatry, 23, 341-346.

Partington, M. W., Tu, J. B., \& Wong, C. Y. (1973). Blood serotonin levels in severe mental retardation. Developmental Medicine and Child Neurology, 15, 616-627.

Perry, E. K., Lee, M. L., Martin-Ruiz, C. M., Court, J. A., Volsen, S. G., Merrit, J., et al. (2001). Cholinergic activity in autism: Abnormalities in the cerebral cortex and basal forebrain. American Journal of Psychiatry, 158, 1058-1066.

Persico, A. M., Militerni, R., Bravaccio, C., Schneider, C., Melmed, R., Conciatori, M., et al. (2000). Lack of association between serotonin transporter gene promoter variants and autistic disorder in two ethnically distinct samples. American Journal of Medical Genetics, 96, 123-127.

Raskind, M. A., Peskind, E. R., Halter, J. B., \& Jimerson, D. C. (1984). Norepinephrine and MHPG levels in CSF and plasma in Alzheimer's disease. Archives of General Psychiatry, 41, 343-346.

Raymond, G., Bauman, M., \& Kemper, T. L. (1996). Hippocampus in autism: A Golgi analysis. Acta Neuropathologica, 91, 117-119.

Research Units on Pediatric Psychopharmacology Autism Network. (2002). Risperidone in children with autism and 
serious behavioral problems. The New England Journal of Medicine, 347, 314-321.

Ritvo, E. R., Yuwiler, A., Geller, E., Ornitz, E. M., Saeger, K., \& Plotkin, S. (1970). Increased blood serotonin and platelets in early infantile autism. Archives of General Psychiatry, 23, 566-572.

Roberts, P. J., Woodruff, G. N., \& Iversen, L. L. (1978). Dopamine. Advances in biochemical psychopharmacology, Vol. 19, New York: Raven Press.

Ross, D. L., Klykylo, W. M., \& Anderson, G. M. (1985). Cerebrospinal fluid levels of homovanillic acid and 5-hydroxyindoleacetic acid in autism. Annals of Neurology, 18, 394.

Ross, D. L., Klykylo, W. M., \& Hitzemann, R. (1987). Reduction of elevated CSF betaendorphin by fenfluramine in infantile autism. Pediatric Neurology, 3, 83-86.

Roy, A., Pickar, D., De Jong, J., Karoum, F., \& Linnoila, M. (1988). Norepinephrine and its metabolites in cerebrospinal fluid, plasma, and urine: Relationship to hypothalamic-pituitary-adrenal axis function in depression. Archives of General Psychiatry, 45, 849-857.

Sandman, C. A. (1988). Beta-endorphin dysregulation in autistic and self-injurious behavior: A neurodevelopmental hypothesis. Synapse, 2, 193-199.

Sandman, C. A. (1991). The opiate hypothesis in autism and self-injury. Journal of Child and Adolescent Psychopharmacology, 1, 237-248.

Sandman, C. A. (1992). Various endogenous opioids and autistic behavior: A response to Gillberg. Journal of Autism and Developmental Disorders, 22, 132-133.

Sandman, C. A., Barron, J. L., Chicz-DeMet, A., \& DeMet, E. M. (1991). Plasma beta-endorphin and cortisol levels in autistic patients. Journal of Autism and Developmental Disorders, 21, 83-87.

Schildkraut, J. J., Orsulak, P. J., Schatzberg, A. F., Gudeman, J. E., et al. (1978). Toward a biochemical classification of depressive disorders. I. Differences in urinary excretion of MHPG and other catecholamine metabolites in clinically defined subtypes of depressions. Archives of General Psychiatry, 35, 1427-1433.

Schroeder, S. R. (1988). Neuroleptic medications for persons with developmental disabilities. In M. G. Aman, \& N. N. Singh (Eds.), Psychopharmacology of the developmental disabilities (pp. 82-100). New York: Springer-Verlag.

Shain, R. J., \& Freedman, D. X. (1961). Studies on 5-hydroxyindole metabolism in autistic and other mentally retarded children. Journal of Pediatrics, 58, 315-320.

Simon, G. B., \& Gillies, S. M. (1976). Some physical characteristics of a group of psychotic children. British Journal of Psychiatry, 110, 104-107.

Sofroniew, M. V., \& Weindl, A. (1981). Central nervous system distribution of vasopressin, oxytosin, and neurophysin. In J. L. Martinez, R. A. Jensen, R. B. Mesing, H. Rigter, \& J. L. McGaugh (Eds.), Endogenous peptides and learning and memory processes (pp. 327-369). New York: Academic Press.

Sponheim, E., \& Skjeldal, O. (1998). Autism and related disorders: epidemiological findings in a Norwegian study using ICD-10 diagnostic criteria. Journal of Autism and Developmental Disorders, 28, $217-227$.

Stahl, S. M. (1996). Essential psychopharmacology: neuroscientific basis and clinical applications. Cambridge, UK: Cambridge University Press.

Steffenberg, S., Gillberg, C., Helgren, L., Anderson, L., Gillberg, L., Jakobsson, G., et al. (1989). A twin study of autism in Denmark, Finland, Iceland, Norway, and Sweden. Journal of Child Psychology and Psychiatry, 30, 405-416.

Stokes, P. E., \& Sikes, C. R. (1987). Hypothalamic-pituitary-adrenal axis in affective disorders. In H. Y. Meltzer (Ed.), Psychopharmacology: The third generation of progress. New York: Raven Press.

Szatmari, P., \& Jones, M. B. (1991). IQ and the genetics of autism. Journal of Child Psychology and Psychiatry, 35, 215-229.

Takahashi, S., Kanai, H., \& Miyamoto, Y. (1976). Reassessment of elevated serotonin levels in blood platelets in early infantile autism. Journal of Autism and Childhood Schizophrenia, 6, 317-326.

Tordjman, S., Anderson, G. M., McBride, P. A., Hertzig, M. E., Snow, M. E., Hall, L. M., et al. (1997). Plasma beta-endorphin, adrenocorticotropin hormone, and cortisol in autism. Journal of Child Psychology and Psychiatry, 38, 705-715.

Tordjman, S., Gutknecht, L., Carlier, M., Spitz, E., Antoine, C., Slama, F., et al. (2001). Role of the serotonin transporter gene in the behavioral expression of autism. Molecular Psychiatry, 6, 434-439.

Trottier, G., Srivastava, L., \& Walker, C. (1999). Etiology of infantile autism: a review of recent advances in genetic and neurobiological research. Journal of Psychiatry and Neuroscience, 24, 103-115.

Volkmar, F. R. (2001). Pharmacological interventions in autism: theoretical and practical issues. Journal of Clinical Child Psychology, 30, 80-87.

Volkmar, F. R., \& Lord, C. (1998). Diagnosis and definition of autism and other pervasive developmental disorders. In F. R. Volkmar (Ed.), Autism and Pervasive Developmental Disorders (pp. 1-31). Cambridge, England: Cambridge University Press. 
Weizman, R., Gil-Ad, I., Dick, J., Tyano, S., Szekely, G. A., \& Laron, Z. (1988). Low plasma immunoreactive beta-endorphin levels in autistics. Journal of the American Academy of Child and Adolescent Psychiatry, 27, 430-433.

Weizman, R., Weizman, A., Tyrano, S., Szekely, B., Weissman, B. A., \& Sarne, Y. (1984). Humoral-endorphin blood levels in autistic, schizophrenic and healthy subjects. Psychopharmacology (Berlin), 82, 368-370.

Werry, J. S., \& Aman, M. G. (1999). Anxiolytics, sedatives, and miscellaneous drugs. In J. S. Werry, \& M. G. Aman (Eds.), Practitioner's guide to psychoactive drugs for children and adolescents (2nd ed., pp. 433-469). New York: Plenum Press.

Whitaker-Azimitia, P. M. (2001). Serotonin and brain development: Role in human developmental diseases. Brain Research Bulletin, 56, 479-485.

Willemsen-Swinkles, S. H. N., Buitelaar, J. K., Weijnen, F. G., Thijssen, J. H., \& Van Engeland, H. (1996). Plasma beta-endorphin concentrations in people with learning disabilities and self-injurious and/or autistic behavior. British Journal of Psychiatry, 168, 105-109.

Winsberg, B. G., Sverd, J., Castells, S., Hurwic, M., \& Perel, J. M. (1980). Estimation of monoamine and cyclic AMP turnover and amino acid concentration of spinal fluid in autistic children. Neuroleptics, 11, 250-255.

World Health Organization. (1994). Diagnostic Criteria for Research (10th Ed.). Geneva: Author.

Yamazaki, K., Saito, Y., Okada, F., Fujieda, T., \& Yamashita, I. (1975). An application of neuroendocrinological studies in autistic children and Heller's syndrome. Journal of Autism and Childhood Schizophrenia, 5, 323-332.

Yirmiya, N., Pilowsky, T., Nemanov, L., Arbelle, S., Feinsiver, T., Fried, I., et al. (2001). Evidence for an association with the serotonin transporter region polymorphism and autism. American Journal of Medical Genetics, 105, 381386.

Young, J. G., Cohen, D. J., Brown, S. L., \& Caparulo, B. K. (1978). Decreased urinary free catecholamines in childhood autism. Journal of the American Academy of Child and Adolescent Psychiatry, 17, 671-678.

Young, J. G., Cohen, D. J., Kavanagh, M. E., Landis, H. D., Shaywitz, B. A., \& Maas, J. W. (1981). Cerebrospinal fluid, plasma, and urinary MHPG in children. Life Sciences, 28, 2837-2845.

Young, J. G., Kavanagh, M. E., Anderson, G. M., Shaywitz, B. A., \& Cohen, D. J. (1982). Clinical neurochemistry of autism and related disorders. Journal of Autism and Developmental Disorders, 12, 147-165.

Ziegler, M. G., Wood, J. H., Lake, R., \& Kopin, I. J. (1977). Norepinephrine and 3-methoxy-4-hydroxyphenyl glycol gradients in human cerebrospinal fluid. American Journal of Psychiatry, 134, 565-568. 